PNL-6698

UC-70

\title{
A Comparison of the Performance of Nuclear Waste Glasses by Modeling
}

\author{
B. Grambow \\ D.M. Strachan
}

December 1988

Prepared for the U.S. Department of Energy under Contract DE-AC06-76RLO 1830

Pacific Northwest Laboratory

Operated for the U.S. Department of Energy

by Battelle Memorial Institute 


\title{
DISCLAIMER
}

This report was prepared as an account of work sponsored by an agency of the United States Government. Neither the United States Government nor any agency thereof, nor Battelle Mernoria! Institute, nor any or their employees, makes any warranty, expressed or implied, or assumes any legal liability or responsibility for the accuracy, completeness, or usefulness of any information, apparatus, product, or process disclosed, or represents that its use would not infringe privately owned rights. Reference herein to any specific commercial product, process, or service by trade name, trademark, manufacturer, or otherwise does not necessarily constitute or imply its endorsement, recommendation, or favoring by the United States Government or any agency thereof, or Battelle Memorial Institute. The views and opinions of authors expressed herein do not necessarily state or reflect those of the United States Government or any agency thereof.

\author{
PACIFIC NORTHWEST LABORATORY \\ operated by \\ BATTELLE MEMORIAL INSTITUTE \\ for the \\ UNITED STATES DEPARTMENT OF ENERGY \\ under Contract DE-AC06-76RLO 1830
}

\begin{tabular}{|c|c|}
\hline \multicolumn{2}{|c|}{ Printed in the United States of America } \\
\hline \multicolumn{2}{|c|}{ Avaldable from } \\
\hline \multicolumn{2}{|c|}{ Nalionad Technical Information Service } \\
\hline \multicolumn{2}{|c|}{ United States Department of Commerce } \\
\hline \multicolumn{2}{|c|}{5285 Port Royal Road } \\
\hline \multicolumn{2}{|c|}{ Springfield, Virginia 22161} \\
\hline \multicolumn{2}{|c|}{ NTIS Price Codes } \\
\hline \multicolumn{2}{|c|}{ Microfiche $A 01$} \\
\hline \multicolumn{2}{|c|}{ Printed Copy } \\
\hline & Price \\
\hline Pages & Codes \\
\hline $001-025$ & $\mathrm{~A} 02$ \\
\hline 1326-050 & $\mathrm{A} 03$ \\
\hline $051-075$ & $\mathrm{~A} 04$ \\
\hline 076.100 & A015 \\
\hline $101-125$ & $\mathrm{~A} 06$ \\
\hline $126-150$ & $\mathrm{~A} 07$ \\
\hline $151-175$ & $\mathrm{~A} 0 \mathrm{~s}$ \\
\hline $176-200$ & $\mathrm{~A} 09$ \\
\hline 201.225 & A10 \\
\hline $226 \cdot 250$ & A11 \\
\hline 251.275 & A 12 \\
\hline $276-300$ & A13 \\
\hline
\end{tabular}


PNL -6698

UC-70

A COMPARISON OF THE PERFORMANCE OF NUCLEAR WASTE GLASSES BY MODELING
B. Grambow (a)
D. M. Strachan

December 1988

Prepared for

the U.S. Department of Energy

under Contract DE-ACO6-76RLO 1830

Pacific Northwest Laboratory

Richland, Washington 99352

(a) Hahn-Meitner Institute, Berlin, Federal Republic of Germany. 

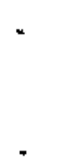

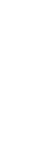




\section{SUMMARY}

Through a combination of data collection and computer modeling, the dissolution mechanism of nuclear waste glasses has been investigated and more clearly defined. Glass dissolution can be described as a dissolution/ precipitation process in which glass dissolves in aqueous solution and solids precipitate as the solubility products are exceeded. The dissolution process is controlled by activity of the rate-limiting specie $\mathrm{H}_{4} \mathrm{SiO}_{4}$. As the concentration of $\mathrm{H}_{4} \mathrm{SiO}_{4}$ increases, the rate of dissolution decreases until a final reaction rate is reached. Between the forward reaction rate (early time) and final reaction rate (very long time), glasses may exhibit an intermediate root time dependence caused by a transport resistance for the diffusion of $\mathrm{H}_{4} \mathrm{SiO}_{4}$ within the gel 1 ayer on the glass surface.

In this report, three glasses are studied: JSS-A, PNL 76-68, and SRL-131. Data from static and dynamic leach tests are assembled, plotted, and successfuily modeled. The kinetic parameters for these glasses are reported. With four parameters derived from experiments for each glass, the model can be used to calculate the effects of changes in the initial composition of the water contacting the glass. The effects of convective flow can also be modeled. Furthermore, glasses of different compositions can be readily compared. 


\section{.}

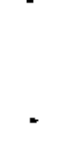




\section{ACKNOWLEDGMENTS}

The work reported here is the result of several years of collaboration beginning in 1981 when B. Grambow worked for 1 year at Pacific Northwest Laboratory (PNL). D. M. Strachan made two visits to the Hahn-Meitner Institute (HMI); one in 1983 and the other in 1985. This exchange was made possible through agreements between the U.S. Department of Energy and the Federal Republic of Germany. Part of the funds to accomplish this study were also provided by the Japanese, Swedish, and Swiss Project.

The authors wish to acknowledge the assistance of several persons who made this work possible. At the HMI, work was carried out in the group headed by $W$. Lutze, who provided laboratory space, technical advice, and reviews of several papers. Frau H. Fuchs assisted us with computer support, and Frau G. Halke provided secretarial support.

At PNL, the work was carried out in groups headed by R. P. Turcotte and G. L. McVay. Support was provided through the Materials Characterization Center and the Performance Assessment Scientific Support Program. Technical discussions and advice have come from M. J. Apted, L. R. Pederson, and B. P. McGrail. Secretarial support has come from C. L. McCutchen and E. D. Golding. Editorial assistance has come from S. R. Gano. 


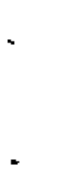




\section{CONTENTS}

SUMMARY .....................

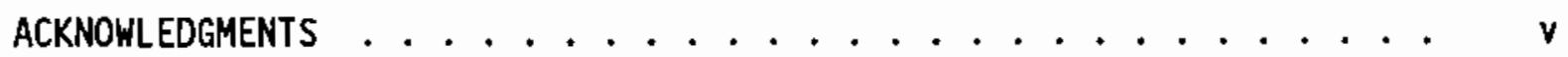

1.0 INTRODUCTION $\ldots \ldots \ldots \ldots \ldots$

2.0 GLASSES EVALUATED . . . . . . . . . . . . . 3

3.0 CONCLUSIONS . . . . . . . . . . . . . . . 5

4.0 GLASS CORROSION MECHANISM AND MODEL ............. 9

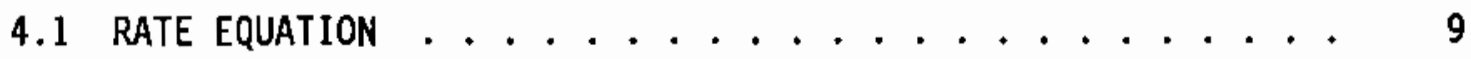

4.2 PARAMETRIC STUDY OF POTENTIAL ALTERATION PRODUCTS . . . . 14

4.3 GLASS SILICA SATURATION . . . . . . . . . . . 18

5.0 EXPERIMENTAL CONDITIONS AND APPLICATION OF THE MODEL . . . . 23

5.1 THERMO-KINETIC ANALYSES OF SOLUTION DATA . . . . . . . 24

5.1.1 Data Analyses for Potential Alteration Products . . . 25

5.1 .2 Saturation Concentration of Silica ....... 32

5.1.3 Rate Constants . . . . . . . . . . . 32

5.2 COMPARISON OF MODEL AND EXPERIMENT . . . . . . . . 35

5.2 .1 JSS-A and ABS-118 ............... 35

5.2 .2 PNL $76-68 \ldots \ldots \ldots \ldots$

5.2 .3 SRL-131 . . . . . . . . . . . . . 38

5.3 EFFECT OF GLASS COMPOSITION ON GLASS DISSOLUTION . . . . . 41

5.4 EFFECT OF SOLUTION COMPOSITION ON GLASS DISSOLUTION . . . 46

6.0 FUTURE WORK .......................... 53

7.0 REFERENCES ......................... 55 


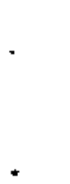




\section{FIGURES}

1 Comparison of Surface Reaction Control and Silica Transport

Control ......................... 11

2 Comparison of Boron Leach Data from Dynamic Tests with Curyes

Calculated by GLASSOL for Diffusion Coeffieients of 1) $10^{-7}$,

2) $\left.\left.10^{-8}, 3\right) 10^{-9}, 4\right) 10^{-10} \mathrm{~cm}^{2} / \mathrm{s} \ldots \ldots 13$

3 Silica Transport Control of Glass Leaching in Flow Test ..... 13

4 Stability Diagrams for Potential Glass Alteration Products

as a Function of Glass Composition; Nontronite and Celadonite

Excluded from List of Potential Phases ........... 16

5 Stability Diagrams for Potential Glass Alteration Products as

a Function of Glass Composition; Nontronite and Celadonite

Included in List of Potential Phases ........... 17

6 Variation of $\log \left(\right.$ IAP) for Silica with $\mathrm{pH}\left(90^{\circ} \mathrm{C}\right)$ for

West Valley GTasses .................. 19

7 Calculated Saturation Indices for JSS-A in Deionized

Water at $90^{\circ} \mathrm{C}$ from Reported Solution Analyses . . . . . . . 28

8 Calculated Saturation Indices for JSS-A in Synthetic

Groundwater at $90^{\circ} \mathrm{C}$ from Reported Solution Analyses . . . . . . 29

9 CaTculated Saturation Indices for JSS-A in Silicate Water

at $90^{\circ} \mathrm{C}$ from Reported Solution Analyses ........... 30

10 Calculated Solution Indices for SRL-131 in Deionized

Water at $90^{\circ} \mathrm{C}$ from Reported Solution Analyses ........ 31

11 Dependence of Leach Rates on the Ion Activity Product

IAP $_{\mathrm{SiO}_{2}}$ of Silica in Leachates .............. 34

12 Comparison of Calculated and Observed Data for JSS-A in

Deionized Water at $90^{\circ} \mathrm{C}$, Static Conditions, and $S / V=10 \mathrm{~m}^{-1} \ldots 36$

13 Comparison of Calculated and Observed Data for JSS-A in

Synthetic Groundwater at $90^{\circ} \mathrm{C}$, Static Conditions, and

$S / V=10 \mathrm{~m}^{-1} \ldots \ldots \ldots . \ldots$

14 Comparison of Calculated and Observed Data for JSS-A in

Silicate Water at $90^{\circ} \mathrm{C}$, Static Conditions, and

$S / V=10 \mathrm{~m}^{-1}$

$15 \mathrm{Calculated} \mathrm{pH}\left(90^{\circ} \mathrm{C}\right)$ as a Function of Time for the

Dissolution of JSS-A in Deionized Water.......... 
16 Comparison of Calculated and Observed Data for ABS-118 in Deionized Water at $90^{\circ} ;$ Flow Rate $=1.8 \mathrm{~mL} / \mathrm{d} \ldots$. . . . . .

17 Comparison of Calculated and Observed Data for PNL 76-68 in Deionized Water at $90^{\circ} \mathrm{C}$, Static Conditions, and $S / V=10 \mathrm{~m}^{-1}$.

18 Calculated $\mathrm{pH}\left(90^{\circ} \mathrm{C}\right)$ as a Function of Time for the Dissolution of PNL 76-68 in Deionized Water; $S / V=10 \mathrm{~m}^{-1}$........

19 Comparison of Calculated and Observed Data for PNL 76-68 in Deionized Water at $90^{\circ} \mathrm{C}$; Flow Rate $=1.8 \mathrm{~mL} / \mathrm{d} \ldots \ldots$

20 Comparison of Calculated and Observed Data for SRL-131 in Deionized Water at $90^{\circ} \mathrm{C}$, Static Conditions, and $S / N=10^{-1}$

21 Comparison of Calculated and Observed Data for SRL-131 in Deionized Water at $90^{\circ} \mathrm{C}$, Static Conditions, and $\mathrm{S} / \mathrm{V}=10^{-1}$.

22 Comparison of Calculated and Observed Data for SRL-131 Dejonized Water at $90^{\circ} \mathrm{C} ; \mathrm{Fl}$ ow Rates $=0 \mathrm{~mL} / \mathrm{d}, 1.8 \mathrm{~mL} / \mathrm{d}$, $15.2 \mathrm{~mL} / \mathrm{d} \ldots \ldots \ldots \ldots . . \ldots . . . \ldots$

23 Comparison of Calculated and Observed Data for SRL-13I in Silicate Water at $90^{\circ} \mathrm{C}$, Static Conditions, and $S / V=10 \mathrm{~m}^{-1} \ldots$

24 Comparison of Calculated and Observed Data for SRL-131 in Synthetic Groundwater at $90^{\circ} \mathrm{C}$, Static Conditions, and $s / V=10 m^{-1} \ldots \ldots \ldots \ldots . . \ldots . . \ldots$

25 Calculated Normalized Boron Mass Loss for JSS-A, PNL 76-68,

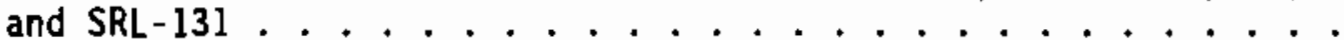

26 Calculated $\mathrm{pH}\left(90^{\circ} \mathrm{C}\right)$ for SRL-131 in Deionized Water, Silicate Water, and Synthetic Groundwater, as a Function of Time .....

27 Calculated $\mathrm{pH}\left(90^{\circ} \mathrm{C}\right)$ for SRL-131 in Deionized Water, Silicate Water, and Synthetic Groundwater, as a Function of Reaction

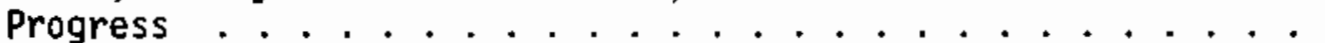


TABLES

1 Composition of JSS-A, ABS-118, PNL 76-68, and SRL-131 . . . . 4

2 Test Conditions of Corrosion Experiments with JSS-A, PNL 76-68, and SRL-131, Which Are Quoted for Comparison with Modeling Results . . . . . . . . . . . . . . . 23

3 Composition of Leachants Used in Quoted Leach Experiments . . . . 24

4 Values of the Kinetic Parameters Used in the Model . . . . . . . 25

5 Set of Alteration Products Used in GLASSOL and PHREEQE to Model the Corrosion Behavior of JSS-A, PNL 76-68, and SRL-131 . . 33 


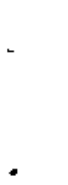




\subsection{INTRODUCTION}

Nuclear fuel processing and reprocessing has generated large volumes of high-level liquid waste, which needs to be immobilized prior to final storage. For immobilization, the waste must be converted to a more insoluble solid and, although other waste forms exist, glass is currently the choice. Once produced, this glass will be sent in canisters to a geologic repository located some 200 to $500 \mathrm{~m}$ below the surface of the earth.

Predicting and ensuring the long-term performance of the waste package, including the glass waste form, is one of the major concerns in building and licensing a nuclear waste repository. Since the time periods of concern are on the order of 10000 years and longer, modeling in addition to physical testing is needed to evaluate waste form behavior. The validation of a model is critical to establishing confidence in long-term predictions and acceptance in the licensing process. Here, validation means to demonstrate the general quantitative applicability of a model to various manmade and natural environments with a variety of glass compositions that can be tested in the laboratory or can be found as natural analogues.

A model selected for the licensing process must be based on a physical/ chemical understanding of the glass corrosion mechanism. Several models for the rate-limiting reaction step have been proposed as being applicable to certain ranges of glass dissolution data. Processes that drew special attention were diffusion in a growing surface layer (Wallace and Wicks 1983); the formation of protective surface films (Hench, Clark, and Yen-Bower 1979; Bunker et a1. 1983; Ma10w 1982); sorption at surface sites (Kuhn and Peters 1983); alkali/hydrogen interdjffusion; and first-order dissolution (Machiels and Pescatore 1982; Harvey, Litke, and Boase 1984). Attempts have also been made to correlate glass durability to the thermodynamic stability of the component oxides and silicates relative to the potential hydration products (Plodinec, Jantzen, and Wicks 1984). With a simple set of variables, none of these models are general enough to account for varying solution chemistry, the presence of waste package components, and various glass compositions; nor can these models be used to describe the dependence of the rate-limiting step on environmental parameters. 
In contrast, a dissolution/precipitation mode] (Grambow 1984) appears to be applicable to experiments with a wide range of solution compositions as well as to more complex systems, such as the bentonite/glass/water system or the steel corrosion product/glass/water system (Grambow 1987) or the dissolution of natural basalt glass in a geologic environment (Grambow et al. 1986b) and, more recently, obsidian glasses (McGrail et al. 1988). This model is based on solution chemistry and transition state theory.

The purpose of this report is to show that the dissolution/precipitation model can be used to better understand the effects of various system variables on glass dissolution. The application and validation of this model is discussed. The theoretical background of the model is briefly presented and is used to describe the dissolution behavior of reference nuclear waste glasses. These reference glasses were selected because they represented a wide range of behavior and, therefore, could be used to illustrate the capabilities of the dissolution/precipitation model. The effects of parameters, such as temperature and starting solution composition, on the dissolution behavior are also discussed. The report further indicates what work is needed to better determine the model parameters and assess the long-term performance of the glass waste form. 


\subsection{GLASSES EVALUATED}

Three representative nuclear waste glasses were selected for a detailed application of the model: JSS-A, PNL 76-68, and SRL-131. Compositions for the individual glasses are given in Table 1.

The JSS-A glass was produced at CEA/Marcoule in France for the Japanese, Swedish, and Swiss Project (JSS 1984). The JSS-A composition comes from the La Hague vitrification $\mathrm{plant}$ using a Pu-enriched light water reactor waste. In the JSS Project, a nonradioactive glass of similar major element composition is also used and is labeled ABS-118.

The PNL 76-68 glass was originally produced for the type of waste that would have come from the Barnwe11, South Carolina, reprocessing plant (Ross et al. 1978) and has been used in many glass dissolution studies. In some corrosion tests, a glass with a slightly higher alkali content was used and was denoted as MCC 76-68. Although A1 is not reported by Strachan (1983), trace amounts of A] have been found in PNL 76-68 glasses. About 0.5 mass\% $\mathrm{Al}_{2} \mathrm{O}_{3}$ was included in the composition of the glass that was modeled.

Although currently replaced by TDS-165 glass, TDS-131 was one of the glasses scheduled for use in the Defense Waste Vitrification Plant at the Savannah River Plant, Aiken, South Carolina (Soper et al. 1983). The composition for the TDS-131 glass from the Savannah River Laboratory was first defined by Plodinec (1980). Like so many other glasses, it has a variable composition depending upon when it was produced and who produced it. The composition shown in Table 1, for instance, differs from that reported by the Materials Characterization Center (MCC 1984), especially in the $\mathrm{Na}, \mathrm{Ca}$, and Si contents. Despite these differences both glasses gave very similar results in corrosion tests (see Section 5.2.3). In this document, TDS-131 is called SRL-131. 
TABLE 1. Composition of JSS-A, ABS-118, PNL 76-68, and SRL-131

\begin{tabular}{|c|c|c|c|c|}
\hline \multirow[b]{2}{*}{ Oxide } & \multicolumn{4}{|c|}{ Composition, wt\% } \\
\hline & $\underline{\mathrm{JSS}-\mathrm{A}}$ & $A B S-118$ & PNL $76-68$ & $\underline{S R L-131}$ \\
\hline $\mathrm{Al}_{2} \mathrm{O}_{3}$ & 4.87 & 4.91 & 0.73 & 3.05 \\
\hline $\mathrm{B}_{2} \mathrm{O}_{3}$ & 14.4 & 14.02 & 9.26 & 9.86 \\
\hline $\mathrm{BaO}$ & & -. & 0.53 & 0.01 \\
\hline $\mathrm{CaO}$ & 4.01 & 4.04 & 2.42 & 1.04 \\
\hline Cdo & -- & -- & 0.05 & - \\
\hline $\mathrm{CeO}_{2}$ & 0.92 & 0.99 & 0.94 & 0.24 \\
\hline $\mathrm{Cr}_{2} \mathrm{O}_{3}$ & - & - & 0.50 & 0.19 \\
\hline $\mathrm{Cs}_{2} \mathrm{O}$ & 1.41 & 1.10 & 0.93 & 0.30 \\
\hline $\mathrm{CuO}$ & -- & -- & 0.06 & 0.03 \\
\hline $\mathrm{Fe}_{2} \mathrm{O}_{3}$ & 2.89 & 2.91 & 9.33 & 14.30 \\
\hline $\mathrm{Gd}_{2} \mathrm{O}_{3}$ & -. & -- & 1.44 & -- \\
\hline $\mathrm{K}_{2} \mathrm{O}$ & -- & -- & -. & 0.12 \\
\hline $\mathrm{La}_{2} \mathrm{O}_{3}$ & 0.89 & 0.89 & 4.06 & 0.33 \\
\hline $\mathrm{LiO}_{2}$ & 1.97 & 1.98 & -- & 3.88 \\
\hline $\mathrm{MgO}$ & -- & -- & -- & 1.24 \\
\hline $\mathrm{MnO}_{2}$ & -- & -- & 0.04 & 4.17 \\
\hline $\mathrm{MoO}_{3}$ & 1.69 & 2.05 & 1.86 & -- \\
\hline $\mathrm{Na}_{2} \mathrm{O}$ & 9.79 & 9.86 & 13.90 & 14.77 \\
\hline $\mathrm{Nd}_{2} \mathrm{O}_{3}$ & 1.58 & 1.52 & -- & 0.45 \\
\hline $\mathrm{NiO}$ & -- & -- & 0.24 & 1.54 \\
\hline $\mathrm{P}_{2} \mathrm{O}_{5}$ & -- & -- & 0.70 & 0.10 \\
\hline $\mathrm{SiO}_{2}$ & 45.15 & 45.48 & 41.50 & 38.63 \\
\hline $\mathrm{SrO}^{\circ}$ & -. & -- & 0.39 & 0.14 \\
\hline $\mathrm{TiO}_{2}$ & - & -. & 3.02 & 0.75 \\
\hline $\mathrm{ZnO}$ & 2.52 & 2.50 & 4.57 & -- \\
\hline $\mathrm{ZrO}_{2}$ & 2.63 & 2.61 & 1.75 & 0.31 \\
\hline $\mathrm{UO}_{2}$ & 0.52 & 0.85 & -- & 1.62 \\
\hline
\end{tabular}

(a) Dashed lines indicate element not present or below detection limit. 


\subsection{CONCLUSIONS}

Glass dissolution apparently can be modeled as congruent dissolution of the glass matrix followed by the precipitation of solid phases with limited solubility. In general, these phases form a reaction or gel layer on the surface of the glass that is often cryptocrystalline. The key species in the dissolution mechanism appears to be $\mathrm{H}_{4} \mathrm{SiO}_{4}$, the concentration of which determines the dissolution rate of the glass. The gel layer on many nuclear waste glasses can form a diffusion zone for the transport of $\mathrm{H}_{4} \mathrm{SiO}_{4}$ to the bulk solution. Because of this diffusion, the $\mathrm{H}_{4} \mathrm{SiO}_{4}$ concentration at the unaltered glass surface can be higher than that observed in the bulk solution. These physical and chemical processes have been adequately modeled using the combination of the PHREEQE geochemical code (Parkhurst, Thorstenson, and Plummer 1980) and the kinetic code GLASSOL (JSS 1987) to account for the changes in the solution chemistry as a function of the amount of glass dissolved, as a function of time, and as a function of the mineral phases that precipitate.

It appears possible to describe the major results from glass dissolution experiments with the use of four parameters and a set of potential alteration products. The parameters are the forward rate of reaction, the long-term or final rate under silica-saturated conditions, the saturation concentration for the glass with respect to $\mathrm{H}_{4} \mathrm{SiO}_{4}$, and the diffusion coefficient in the

gel layer for the rate-limiting specie $\mathrm{H}_{4} \mathrm{SiO}_{4}$. Although the forward rate can be estimated using the Gibbs free energies of hydration (Grambow 1985; Plodinec, Jantzen, and Wicks 1984), the four parameters are best obtained from specific experiments. Published data were used in determining these parameters for each of the glasses studied here.

Currently, ideal alteration phases are being used in the model because there is a lack of good information on the composition of the phases actually formed. For sparingly soluble glass constituents, this assumption may cause some discrepancies between calculated and observed solution concentrations. As more information becomes available, the thermodynamic data for these phases can be included into the PHREEQE data base to refine the model and yield better agreement between the calculations and the observations. With 
the information currently available, and the four kinetic parameters, the behavior of nuclear waste glasses can be compared, and a semiquantitative understanding of their long-term behavior can be obtained.

The forward rates of reaction for the glasses evaluated in this study (JSS-A, PNL 76-68, and SRL-131) were about equal at $90^{\circ} \mathrm{C}$, ranging from $1.5 \mathrm{~g} /\left(\mathrm{m}^{2} \cdot \mathrm{d}\right)$ to $3.0 \mathrm{~g} /\left(\mathrm{m}^{2} \cdot \mathrm{d}\right)$. Similarly, the saturation with respect to the glass ranged from a $\log K^{*}$ of -2.934 to -2.715 for JSS-A and PNL 76-68, respectively. In other words, there is not more than a factor of 2 difference between these parameters for the three glasses. The large difference between the glasses was in the diffusion coefficients and the apparent final reaction rates. The diffusion coefficients ranged from $10^{-9} \mathrm{~cm}^{2} / \mathrm{s}$ to $10^{-7} \mathrm{~cm}^{2} / \mathrm{s}$ for JSS-A and PNL 76-68, respectively. There was about a factor of 10 difference between the final rate of reaction for JSS-A and SRL-131. The subtle interplay of all four kinetic parameters, glass composition, and solution composition accounts for the observed differences in durability of the three glasses. This difference in durability may be illustrated by the comparison between SRL-131 and JSS-A. Both glasses have similar log $\mathrm{K}_{\text {sat, }}$, but because SRL-131 contains more $\mathrm{Na}$, the leachate $\mathrm{pH}$ is more alkal ine than for the JSS-A, and more SRL-131 must dissolve to reach saturation.

Al though the work reported here is comprehensive, there are critical tests that need to be performed. Of the three glasses studied, JSS-A has the most complete data set. Hence, the four parameters for JSS-A are known accurately. To make a better statement about the general behavior of glasses in contact with aqueous solutions, more work is necessary on glasses of other compositions. Furthermore, more work is needed to define the role of other ions in solution, e.g., $\mathrm{Pb}, \mathrm{Al}$, and $\mathrm{Mg}$, in relation to the kinetic parameters.

The most important unknown in glass composition and in the use of the model for long-term predictions is the nature of the final reaction. A constant final rate is used in the model as a "black box" that describes the dissolution process under silica-saturated conditions. It is not known if 
the rate decreases with time. For example, the value of the final rate for JSS-A has decreased by more than a factor of 10 as more data at high $S / V$ become available (JSS 1987).

Another result of the present study is that the effect of the initial solution composition of nonbrine groundwaters seems to be of minor importance for glass corrosion. Provided that the groundwater flow rates are low, the solution chemistry will be dominated by the glass/water reaction and not by the initial groundwater composition. 


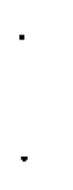




\subsection{GLASS CORROSION MECHANISM AND MODEL}

In contrast to $\mathrm{Na}^{+} / \mathrm{H}^{+}$interdiffusion on the surface of alkali silicate glasses, network or matrix corrosion is much more important in the reaction between nuclear waste glass and aqueous solution. Network formers, such as $B$, are released from the glass to the same extent as network modifiers such as the alkali ions. In other words, for $\mathrm{Na}^{+} / \mathrm{H}^{+}$interdiffusion, steady-state matrix conditions are reached almost instantaneously. The release of soluble glass constituents is controlled by matrix dissolution, whereas the solution concentrations of sparingly soluble elements, such as $\mathrm{Zr}$ or Al, are limited by solubility or sorption processes (Grambow 1982; Strachan, Krupka, and Grambow 1984). The latter elements form surface layers of sparingly soluble glass constituents on the glass.

Static leach tests often demonstrate that the corrosion rate of glasses decreases with time. Initially, this effect was explained by the formation of surface layers acting as a protective barrier (Malow 1982; Clark et al. 1982). However, several investigators have shown that these layers are usually nonprotective (Chick and Pederson 1984; Grambow and Strachan 1984; Conradt, Roggendorf, and Scholze 1986). Instead, the rate of reaction decreases because of "saturation" of silica in solution. This decrease can be described mathematically by a dissolution reaction, which is first order with respect to silica (Grambow 1983a,b; Strachan 1984; Barkatt et a1. 1985). Since glass is not a thermodynamically stable phase, "saturation" cannot mean equilibrium. Results from glass powders and from tests at high temperatures show that glass corrosion continues at a low rate despite "silica saturation" (Grambow 1983a,b; Fullam 1982; Conradt, Roggendorf, and Scholze 1986; Freude et a1. 1985).

\subsection{RATE EQUATION}

To describe the corrosion of $g$ lasses, a general rate equation has been proposed by Grambow (1984) to account for the effects of temperature, glass, and solution composition. This equation is based on equilibrium and irreversible thermodynamics and on transition state theory. In its simplest 
form this equation is similar to those reported by Wallace and Wicks (1983); Strachan (1984); and Chick and Turcotte (1983) and may be described as follows:

$$
r_{m}=k_{+} \cdot\left(1-a_{S i} / a_{s a t}\right)
$$

where $r_{m}=$ the dissolution rate of the glass matrix

$k_{+}=$the rate constant for the forward reaction

${ }^{a} \mathrm{Si}=$ the actual activity of orthosilicic acid in solution

$a_{\text {sat }}=$ the corresponding activity at saturation.

The effect of temperature can be described in part by an Arrhenius dependence for $k_{+}$:

$$
k_{+}=A \cdot \exp \left(-E_{A} / R T\right)
$$

where $E_{A}=$ the activation energy

$T=$ the absolute temperature

$R=$ the gas constant

$A=$ the pre-exponential factor $\left(k_{+}\right.$at $\left.t_{\infty}\right)$.

In some cases, the rate was dependent on the growth of a surface layer (i.e., Grambow and Strachan 1984). This effect was explained by transport control of dissolved silica (Grambow et al. 1986a; Wallace and Wicks 1983). Whether surface layers play an important role in the kinetics of glass corrosion depends on the relative rates of $\mathrm{H}_{4} \mathrm{SiO}_{4}$ transport and glass dissolution. In Figure 1, the effect of surface reaction control and transport control is compared (JSS 1987; Grambow 1987). Transport of dissolved silica through the surface layer may be described by the following equation (Grambow et al. 1986a):

$$
r_{m}=k_{+} \cdot\left(1-a_{s i, s} / a_{s a t}\right)=D / L\left(a_{s i, s}-a_{s i, b}\right)+r_{f i n}
$$

where ${ }^{a} \mathrm{Si}_{, b}=$ bulk solution activity of $\mathrm{H}_{4} \mathrm{SiO}_{4}$, mol/L

$$
{ }^{a} \mathrm{Si}, \mathrm{s}=\mathrm{H}_{4} \mathrm{SiO}_{4} \text { activity at the glass surface, mol/L }
$$


Surface Reaction Control

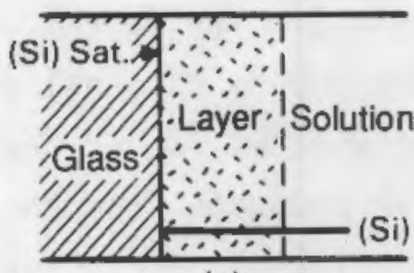

(a)

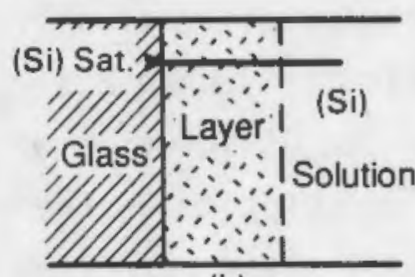

(b)

Silica Transport Control

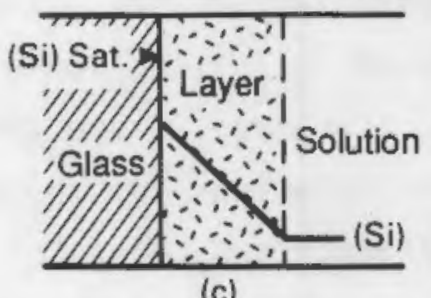

(c)

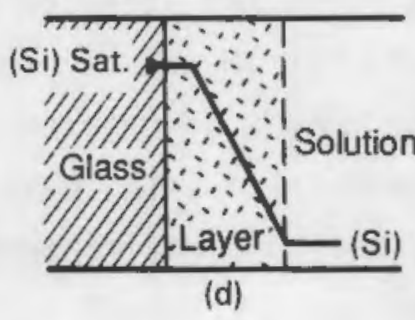

FIGURE 1. Comparison of Surface Reaction Control and Silica Transport Control. Concentration profiles of $\mathrm{H}_{4} \mathrm{SiO}_{4}$ at the phase boundary;

$(a, c) \mathrm{H}_{4} \mathrm{SiO}_{4}$ less than saturation and (b,d) $\mathrm{H}_{4} \mathrm{SiO}_{4}$ at saturation.

$$
\begin{aligned}
D= & \text { diffusion coefficient of } \mathrm{H}_{4} \mathrm{SiO}_{4} \text { in the growing surface layer, } \\
& \mathrm{cm}^{2} / \mathrm{s} \\
L= & \text { layer thickness, cm } \\
r_{\text {fin }}= & \text { final rate of glass dissolution at } \mathrm{H}_{4} \mathrm{SiO}_{4} \text { saturated } \\
& \text { conditions; } i . e ., a_{S i, s} \text { is constant. }
\end{aligned}
$$

Equation (1) has been included in Equation (3), but the silicic acid activity is the value in the surface layer rather than in the bulk solution. A FORTRAN code GLASSOL. was developed for the numerical integration of Equation (3) (Grambow 1987). The effects of the specimen surface area to solution volume ratio $(S / V)$, flow rate, temperature, time, solution chemistry, and waste package components (bentonite and corrosion products) have been considered (Grambow 1987).

The constants $k_{+}$, a $a_{\text {sat }}, D$, and $r_{\text {fin }}$ must be derived from experiments, although an estimate of $K_{+}$may be obtained from the $\Delta G$ of the glass (JSS 1987). The silicic acid activity, a $s j$, depends on the overall reaction path of glass dissolving in aqueous solutions, and the reaction path may be quite 
complicated because $\mathrm{H}_{4} \mathrm{SiO}_{4}$ may be involved in secondary reactions (i.e., hydrolysis, precipitation of silicates, etc.). The degree of complication increases particularly when $\mathrm{H}_{4} \mathrm{SiO}_{4}$ is supplied by external sources, such as groundwater or the dissolution of bentonite backfill, or when it is consumed, for instance, by sorption on the corrosion products from the steel container. The dependence of these reactions on the solution concentration of $\mathrm{H}_{4} \mathrm{SiO}_{4}$ with increasing amounts of reacted glass is calculated with the geochemical computer code PHREEQE (Parkhurst, Thornstenson, and Plummer 1980). The calculations also yield the solution concentrations of the other major glass constituents and the amount of precipitated solid reaction products as a function of the amount of reacted glass. Constraints are the initial glass and solution composition, the mass action equations for the solubility of solid precipitates, and environmental parameters such as the temperature and the solution volume. Critical to these calculations is the correct selection of potential alteration products (see Section 4.2).

The effect of volumetric flow rate, $F$, on glass dissolution is included in GLASSOL and is given by:

$$
d C_{G} / d t=(S / V) \cdot r_{m}-(F / V) \cdot C_{G}
$$

where $C_{G}$ is the amount of glass reacted, expressed in units of concentration, and $r_{m}$ is calculated by Equation (2). The calculated time dependence of the solution concentration of leached glass constituents in a flow test is illustrated in Figures 2 and 3 . The illustrated curves and data are for ABS-118 (see Table 1 for the composition).

As shown by the curves in Figure 2, the solution concentration in leach tests with flowing solutions depends on the diffusion coefficient, D, of $\mathrm{H}_{4} \mathrm{SiO}_{4}$ (Equation 3 ) in the surface layer. Thus, a comparison of data from flow tests with a set of calculated curves can be used to estimate the $\mathrm{H}_{4} \mathrm{SiO}_{4}$ diffusion coefficient in the surface layer. Solution concentrations decrease with time because $\mathrm{H}_{4} \mathrm{SiO}_{4}$ in the growing surface layer increases more rapidly than that in bulk solution (Figure 3 ). The rapid increase is due to the diffusive transport resistance in the growing surface layer. Thus, "saturation" 


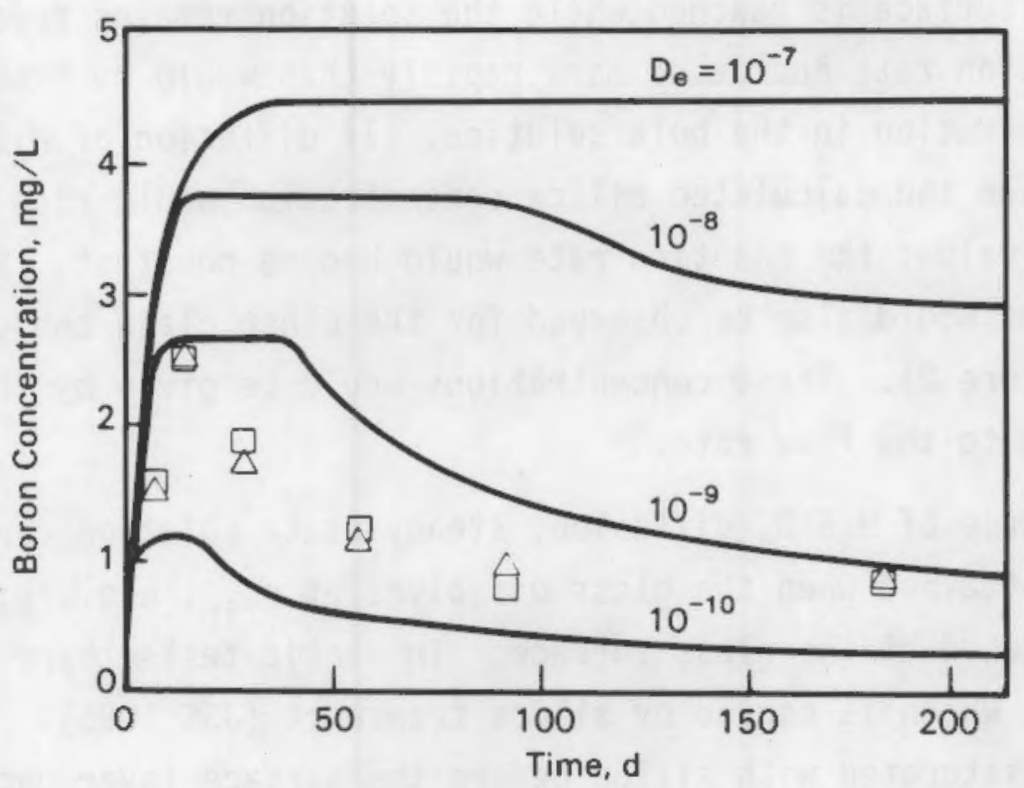

FIGURE 2. Comparison of Boron Leach Data from Dynamic Tests (Example: ABS-118 in Deionized Water, $2.9 \mathrm{~mL} / \mathrm{d}, \mathrm{S} / \mathrm{V}=10 \mathrm{~m}^{-1}$, Vol = $39 \mathrm{~mL}$ ) with Curves Calculated by GLASSOL for Diffusion Coefficients of 1) $10^{-7}$, 2) $\left.10^{-8}, 3\right) 10^{-9}$, 4) $10^{-10} \mathrm{~cm}^{2} / \mathrm{s}$.

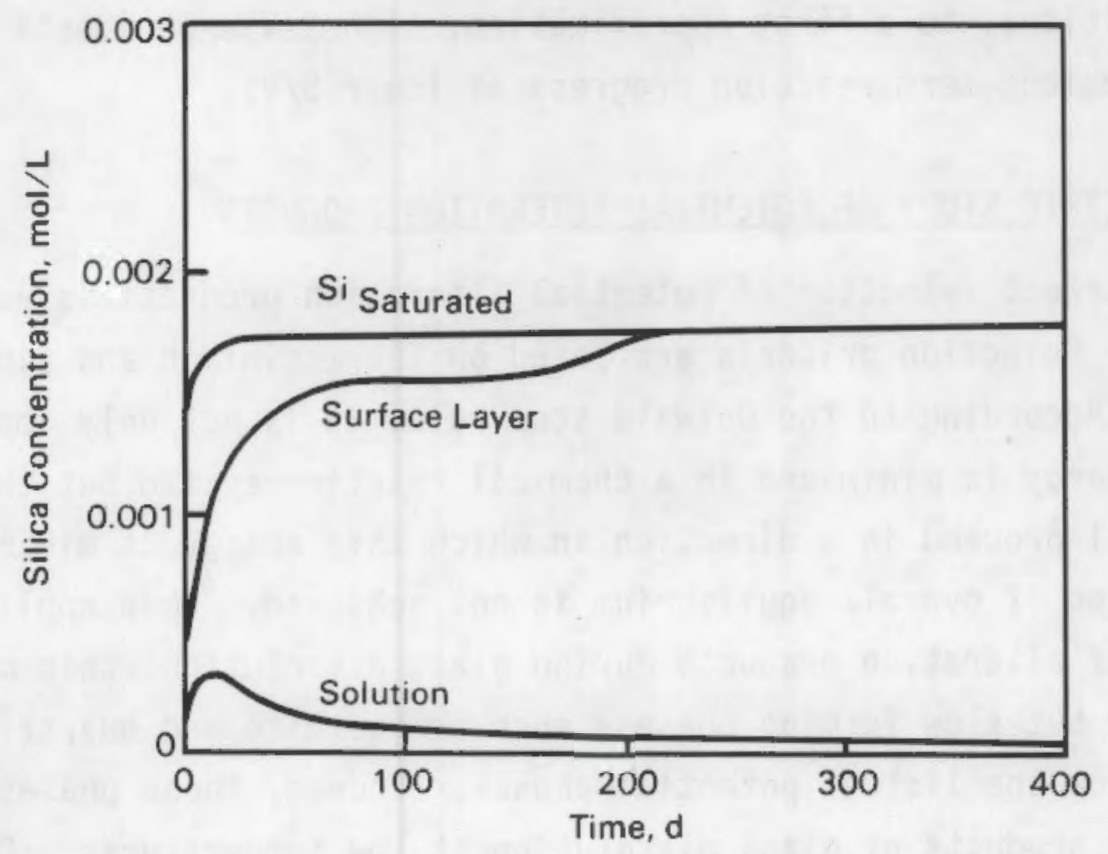

FIGURE 3. Silica Transport Control of Glass Leaching in Flow Test (Same Data as for Curve 3 in Figure 2). Calculated curves for the total silica concentration in bulk solution and in the surface layer are compared with the saturation concentration. 
at the glass surface is reached while the solution remains undersaturated, and the reaction rate decreases more rapidly than would be expected from the silica concentration in the bulk solution. If diffusion of $\mathrm{H}_{4} \mathrm{SiO}_{4}$ were neglected, then the calculated silica concentration would rise rapidly to a steady-state value; the reaction rate would become constant. Steady-state concentrations would also be observed for the other glass components (Curve 1, Figure 2). These concentrations would be given by the ratio of the reaction rate to the flow rate.

In the case of $\mathrm{H}_{4} \mathrm{SiO}_{4}$ diffusion, steady-state solution concentrations can only be attained when the glass dissolves at $\mathrm{r}_{\text {fin }}$; e.g., $\mathrm{H}_{4} \mathrm{SiO}_{4}$ saturation is reached at the glass surface. In static tests there is only a minor effect, which is caused by silica transport (JSS 1986). The bulk solution becomes saturated with silica before the surface layer becomes thick enough to limit the transport of dissolved silica. This explains why, in most static leach tests, the surface layers of nuclear waste glasses often are found to be nonprotective and why often there is a good correlation between the solution concentration of glass constituents and $(s \cdot t) / V$. Under these conditions, to a first approximation, high $S / \mathrm{V}$ experiments can be used to simulate long-term reaction progress at lower $S / \mathrm{V}$.

\subsection{PARAMETRIC STUDY OF POTENTIAL ALTERATION PRODUCTS}

The correct selection of potential alteration products is essential for the model. Selection criteria are based on thermodynamic and kinetic constraints. According to the 0stwald step rule, it is not only important that the free energy is minimized in a chemical reaction system but that the reaction(s) will proceed in a direction in which this energy is minimized most rapidly, even if overall equilibrium is not achieved. When applied to the formation of alteration products during glass dissolution, this means that very stable but slow forming phases, such as goethite and quartz, must be excluded from the list of potential phases. Indeed, these phases are rarely observed as products of glass dissolution at low temperatures. Preselection of phases is also important because a geochemical code such as PHREEQE will select the most stable phase to precipitate first, whereas less ordered, more rapidly forming phases will precipitate in experiments. 
To demonstrate the sensitivity of the modeling results to the assemblage of alteration products, a parametric study was performed by varying a hypothetical glass through a range of 30 compositions. Stability fields were then determined for the alteration products. The glass composition was varied by keeping the sum of $\mathrm{Si}$ and $\mathrm{Na}$ constant at 70 cation \%. The $\mathrm{Si}$ content was varied from 30 to 50 cation \%. The Al content was 6 cation \% for high $\mathrm{Al}$ glasses and 2 cation \% for low $\mathrm{Al}$ glasses. Both $\mathrm{Ca}$ and $\mathrm{Mg}$ were kept constant at 2 cation \% and $\mathrm{Fe}$ at 10 cation \%.

For the hypothetical glass compositions in this study, the reaction path was calculated for $3 \cdot 10^{-4}$ to $3 \cdot 10^{-2}$ moles of glass dissolved per liter of deionized water. All calculations were performed for a temperature of $90^{\circ} \mathrm{C}$, assuming equilibrium with ambient $\mathrm{CO}_{2}$. For the calculations, a 1 ist of phases that are often formed as alteration products on weathered basalt glass was chosen that included analcime $\left[\mathrm{Na}\left(\mathrm{AlSi}_{2} \mathrm{O}_{6}\right) \mathrm{H}_{2} \mathrm{O}\right]$; gibbsite $\left[\mathrm{Al}(\mathrm{OH})_{3}\right]$; montmorillonite $\left[\mathrm{Na}_{0.3}\left(\mathrm{Si}_{3.96} \mathrm{Al}_{0.04}\right)\left(\mathrm{Al}_{1.55} \mathrm{Fe}_{0.2} \mathrm{Fe}_{0.01} \mathrm{Mg}{ }_{0.24}\right) \mathrm{O}_{10}(\mathrm{OH})_{2}\right]$; saponite $\left[\mathrm{Na}_{0.33}\left(\mathrm{Al}_{0.33} \mathrm{Si}_{3.67}\right) \mathrm{Mg}_{3} \mathrm{O}_{10}(\mathrm{OH})_{2}\right]$, celadonite $\left[\mathrm{Na}_{0.76} \mathrm{Ca} 0.06{ }_{0.80}\left(\mathrm{Si}_{3.80}\right.\right.$ $\left.\left.\mathrm{Al}_{0.67} \mathrm{Fe}_{0.96} \mathrm{Mg}_{0.62}\right)_{10}(\mathrm{OH})_{2}\right]$; nontronite $\left[\mathrm{Ca}_{0.1} \mathrm{Na}_{0.25}\left(\mathrm{Si}_{3.84} \mathrm{Al}_{0.94} \mathrm{Fe}_{0.9}\right.\right.$ $\left.\left.\mathrm{Mg}_{0.33}\right)_{10}(\mathrm{OH})_{2}\right]$; and $\mathrm{SiO}_{2}$. The calculations were performed with and without celadonite and nontronite to study the degree that the predicted phase formation depended on the selection of potentially precipitating phases.

Figure 4 shows the results of calculations for high- and low-Al glasses without including celadonite and nontronite, whereas in Figure 5, nontronite and celadonite are allowed to precipitate. The following observations can be made:

1. Without celadonite and nontronite - In low-Al glasses (Figure 4b), saponite is the first phase to form, independent of the Si:Na ratio, and gibbsite does not form. In high-Al glasses (Figure 4a), gibbsite is formed first. In the case of high-alkali glasses, gibbsite forms when slightly more glass dissolves, because of the higher gibbsite solubility at higher solution $\mathrm{pH}$. The formation of gibbsite does not influence the formation of saponite. Montmorillonite is the next phase to form in high-silica glasses, irrespective of the Al content. Both montmorillonite and saponite coexist and cause the dissolution of gibbsite. 


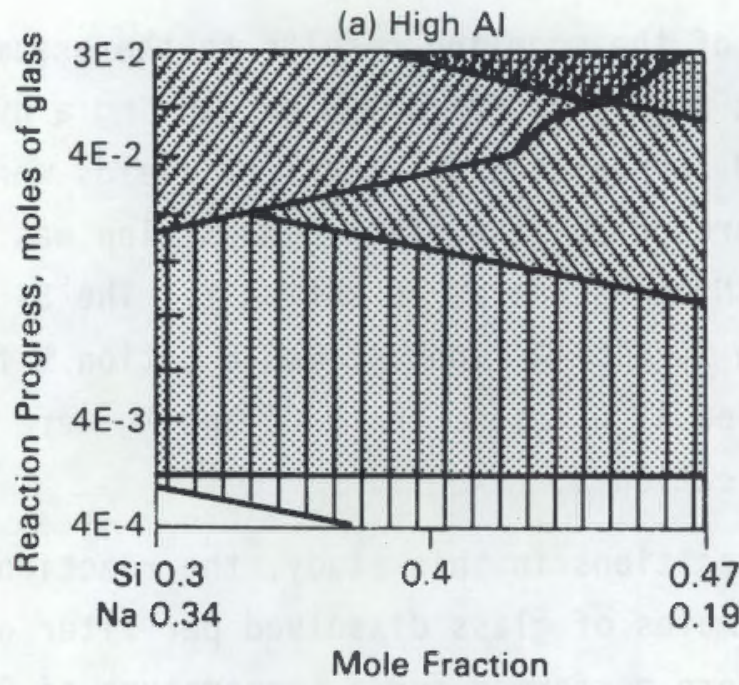

ZIIIDAnalcime

SIIVW Wyoming Montmorillonite \%: (b) Low Al

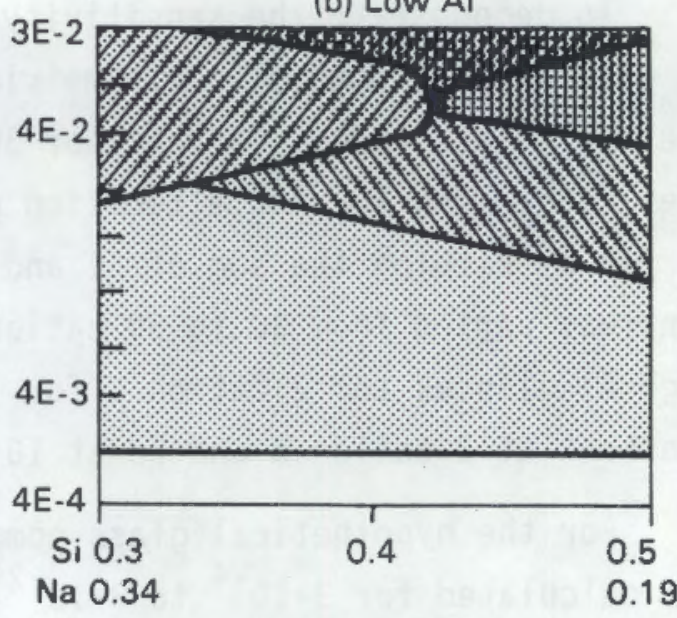

Mole Fraction

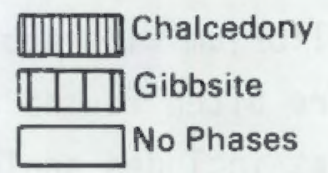

FIGURE 4. Stability Diagrams for Potential Glass Alteration Products as a Function of Glass Composition; Nontronite and Celadonite Excluded from List of Potential Phases.

(a) high Al-containing glasses (6 cation \%); (b) low Al-containing glasses ( 2 cation \%).

Analcime formation is favored by high-alkali glasses, but depending on the alkali content, montmorillonite may or may not be a precursor for analcime. These two phases do not coexist, but analcime coexists with saponite. Silica saturation is reached earlier for high-silica glasses than for low-silica glasses. In general, silica saturation is also reached earlier in low-Al glasses, probably because a significant amount of $S i$ is tied up in the formation of aluminum silicates in high-Al glasses.

2. With celadonite and nontronite included - The conditions of phase formation change completely when nontronite and celadonite are included in the calculations (Figures $5 \mathrm{a}, \mathrm{b}$ ). In all cases, celadonite is the first phase to precipitate. Saponite and montmorillonite formation is suppressed in all cases, and analcime forms only at very high reaction progress and only within the range of reaction progress studied in high-Al glasses. The stability 

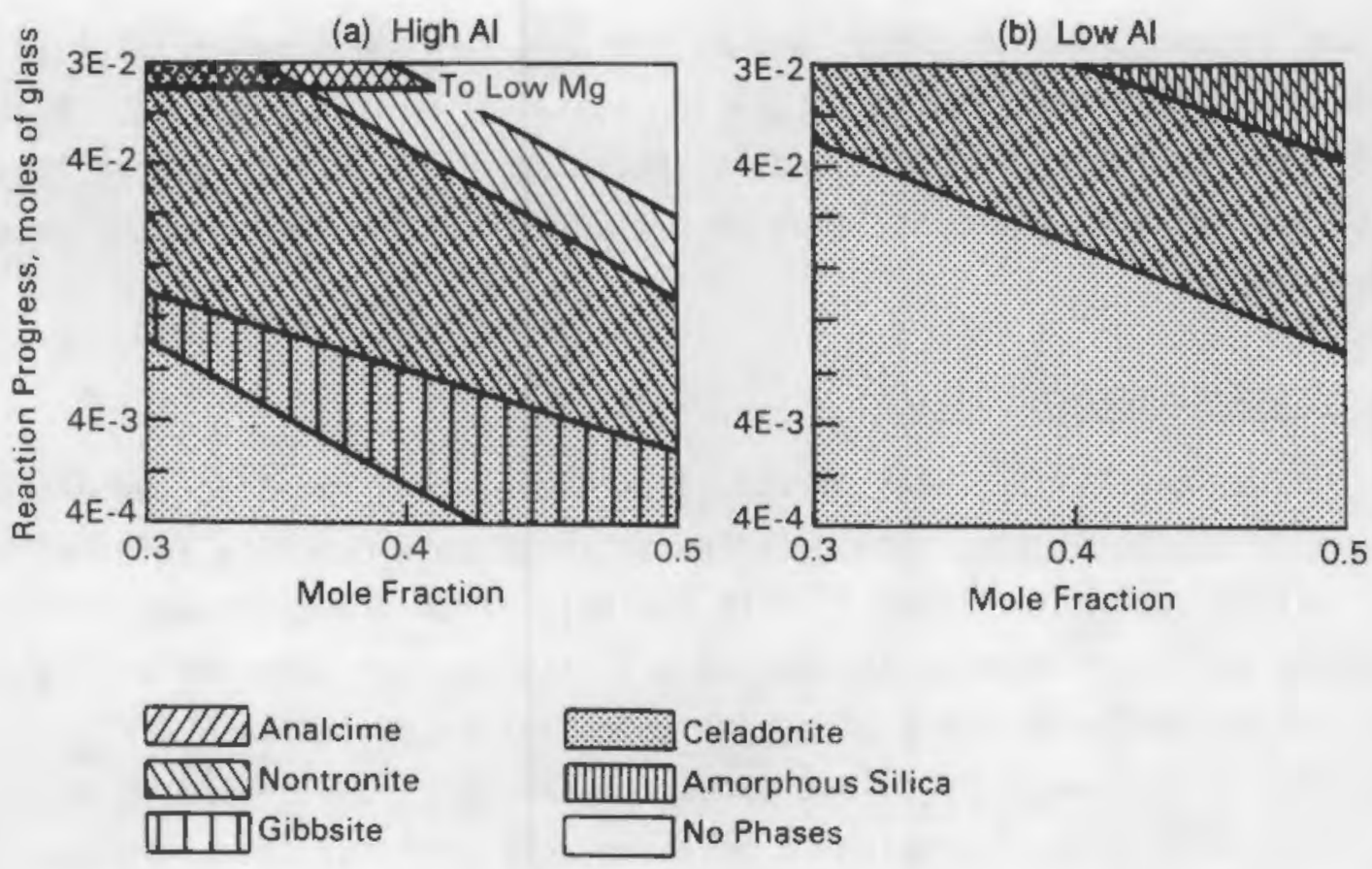

EIGURE 5. Stability Diagrams for Potential Glass Alteration Products as a Function of Glass Composition; Nontronite and Celadonite Included in List of Potential Phases

field for the formation of gibbsite becomes smaller. Gibbsite can coexist with celadonite but not with nontronite. The formation of nontronite depends on both the AT and the Si content of the glass. In high-silica and high-Al glasses, nontronite is formed earlier, whereas in low-Al, low-silica glasses, nontronite is formed rather late.

The results of this parametric study show that the exact composition of the predicted alteration phase assemblage is a complicated function of glass composition and of the choice of minerals considered. Consequently, to constrain the selection, the experience from three major sources must be considered: 1) the occurrence of minerals in geochemical mineral alteration sequences, for example, gibbsite, montmorillonite, or goethite. The formation of celadonite during basalt glass alteration in seawater, for example, may be kinetically hindered for millions of years (Pritchard, Cann, and Wood 1978). 2) the solid-state analysis of alteration products formed in experiments on nuclear waste glasses, for example, analcime and montmorillonite 
(Lutze, Malow, and Rabe 1983), and 3) the chemical modeling of solution analyses with respect to the saturation state of various minerals. Minerals like goethite, which may be found in natural systems but are generally supersaturated in such solutions, must be excluded from the selection of phases considered.

\subsection{GLASS SILICA SATURATION}

One of the key features of the glass dissolution model is the decrease in the glass dissolution rate with the approach to a quantity referred to as the "silica saturation limit." With the help of the PHREEQE code, this quantity can be calculated as the ion activity product (IAP) of silica from the analysis of solutions that appear to be saturated $\left(\mathrm{IAP}_{\mathrm{SiO}_{2}}=\mathrm{K}_{\mathrm{sat}}\right)$. In this regard, the value $K_{\text {sat }}$ is a purely empirical parameter and is equal to the total silica concentration in solution corrected for the hydrolysis of silicic acid. For modeling, this experimentally determined constant is sufficient. However, to understand this quantity, it is necessary to evaluate which parameter will influence it.

In this section, a large number of solution data is studied from a wide variety of glass compositions to determine if the saturation of the glass surface is a sensitive function of the solution $\mathrm{pH}$ and the $\mathrm{Al}$ content of the $\mathrm{glass}$. The data originate from a parametric study of more than $100 \mathrm{glass}$ compositions (Chick et al. 1984). For these glasses, results from 28-day MCC -3 tests (MCC 1981) were reported. In many cases, the high S/V of these experiments favors attainment of saturation and, therefore, the data may be useful for the current study.

The solution data were used as input to the PHREEQE code. The $\log$ (IAP) for $\mathrm{SiO}_{2}$ at $90^{\circ} \mathrm{C}$ was calculated for each solution and was plotted against the solution $\mathrm{pH}$ calculated for $90^{\circ} \mathrm{C}$ (Figure 6 ). The $\mathrm{pH}$ at test temperature was calculated from the room-temperature $\mathrm{pH}$ reported by Chick et al. (1984). Although there is a lot of scatter in the data, a clear trend appears with respect to $\mathrm{pH}$. However, glasses with high Al (inverted triangles in Figure 6) yield solutions with $\mathrm{pH}$ values ranging from low to high as do glasses with low Al content (squares in Figure 6 ). There is no clear effect of Al 


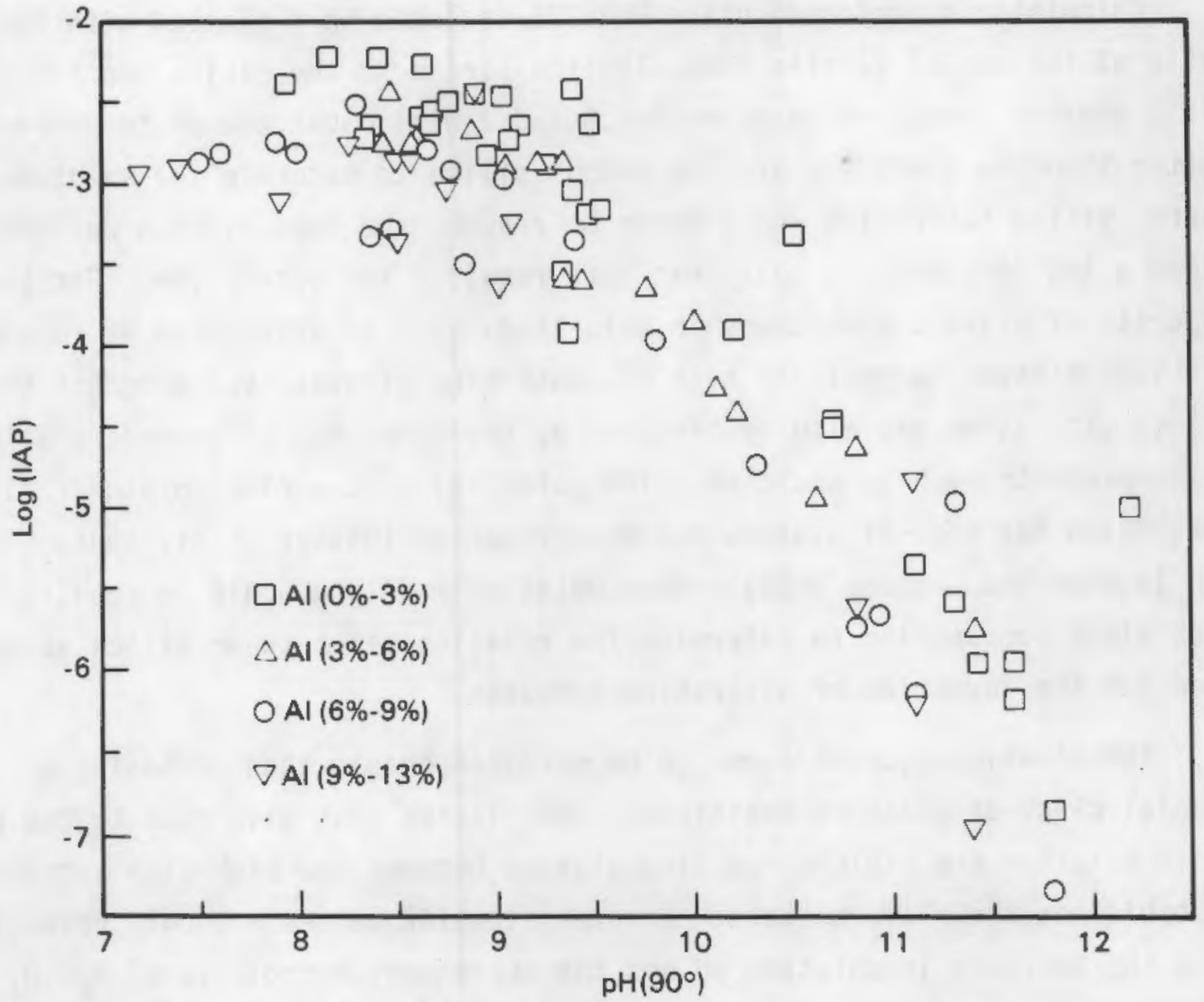

FIGURE 6. Variation of $\log \left(\right.$ IAP) for Silica with $\mathrm{pH}\left(90^{\circ} \mathrm{C}\right)$ for West Valley Glasses (Chick et al. 1984)

within the scatter of the data, but an effect of $\mathrm{pH}$ is apparent. At $\mathrm{pH}\left(90^{\circ} \mathrm{C}\right)$ values lower than 9 , the $\log$ (IAP) does not vary significantly. On the other hand, above $\mathrm{pH}\left(90^{\circ} \mathrm{C}\right)=9$, the $\log ($ IAP) and, hence the concentration of $\mathrm{H}_{4} \mathrm{SiO}_{4}$, decreases, even though the total silica content in solution increases with $\mathrm{pH}$. Various possible explanations can be given for this behavior. Either a special class of glass compositions exists which, during corrosion, drives the $\mathrm{pH}$ to high values and has a low saturation concentration, or saturation was not reached for these glasses because reaction rates were too low. A change in the glass dissolution mechanism at high $\mathrm{pH}$ values is also a possibility. Furthermore, the possibility cannot be excluded that some of these glasses would completely dissolve before the saturation concentration could be reached. 
Calculations performed using PHREEQE indicate that glasses with the ratio of the sum of alkalis plus alkaline earths to the silica content of the glass greater than a value between 1.5 and 2 will cause the $\mathrm{pH}$ to increase faster than the glass can provide enough silica to saturate the solution. Hence, silica saturation would never be reached and the solution would always yield a $\log$ (IAP) that is less than that required for saturation. For the majority of glass compositions in this study such an effect can be ruled out. For some glasses, especially high Al-containing glasses, the approach to silica saturation may also be hindered by the formation of secondary alteration products such as analcime. The potential of analcime to hinder silica saturation for high-Al glasses has been reported (Haaker et al. 1985;

Van Iseghem and Grambow 1988). More detailed modeling would be required for each glass composition to determine the relationship between silica saturation and the formation of alteration products.

The kinetic argument seems to be more reasonable than proposing a special class of glass compositions. The glasses that give rise to the high $\mathrm{pH}$ in solution are rapidly reacting glasses because the high alkali content destabilizes the glass network. However, low IAP values are only possible when the increase in solution $\mathrm{pH}$ and the subsequent hydrolysis of $\mathrm{H}_{4} \mathrm{SiO}_{4}$ are faster than the accumulation of dissolved silica. The observed linear decrease of $\log ($ IAP) with increasing $\mathrm{pH}$ (slope of -1 in Figure 6) could be expected when, with the increasing $\mathrm{pH}$, the rate of glass dissolution remains nearly constant within the scatter of the data. Thus, above $\mathrm{pH} \mathrm{9,} \mathrm{each} \mathrm{unit}$ increase in the $\mathrm{pH}$ increases the fraction of $\mathrm{H}_{4} \mathrm{SiO}_{4}^{-}$of the total silica content by a factor of 10 , and when the total amount of silica in solution increases only slightly, the IAP value decreases by a factor of 10 . Constant forward reaction rates are unlikely because of the increasing alkali content of the glasses. However, silica transport control through growing reaction layers may have the effect of leveling the reaction rates for these glasses. Thus, in a 28-day test, even with a powdered glass specimen, the relative glass dissolution rate is low compared with the time that the test is allowed to run and the large amount of glass that must dissolve so that the solution becomes saturated with respect to the glass. If the test were continued for 
a longer period of time and the calculations repeated, the $\mathrm{pH}$ independent line in Figure 6 would extend to higher $\mathrm{pH}$ values.

From this analysis, there does not appear to be a significant effect of Al on the silica saturation value. This means that the beneficial effect of $A 1$ on the reaction rate of glasses can be attributed to its effect on either the forward rate of reaction or the diffusion coefficient in surface layers.

A number of authors have demonstrated that other ions have major impacts on the dissolution of glass, for example, Mg (Grambow and Strachan 1984) and $\mathrm{Pb}$ (Buckwalter and Pederson 1982; Barkatt et a1. 1985). Whether this is an effect on the basic mechanism, i.e., changing the activated complex and the saturation concentration, or on the transport of $\mathrm{H}_{4} \mathrm{SiO}_{4}$ is not clear at this point. 



\subsection{EXPERIMENTAL CONDITIONS AND APPLICATION OF THE MODEL}

The dissolution behavior of JSS-A, PNL 76-68, and SRL-131 has been studied by many research groups. Four data sets were used from the literature. For the JSS-A, data were obtained from the JSS Project (JSS 1984, $1986,1987)$. The SRL-131 dissolution data for static tests in a variety of solutions were obtained from Strachan, Pederson, and Lokken (1985) for up to 2 years and up to 4 years from Wicks et al. (1986) for deionized water only. Flow data were reported by Strachan (1984) from the MCC-4 Low Flow Test Method (MCC 1981). Dissolution data for PNL 76-68 in static tests were obtained from Strachan (1983), while the flow data were reported by Strachan and Exarhos (1981). Table 2 shows the summary of the conditions for each of the modeled solutions and glasses, and Table 3 contains the composition of the various leachants used in the experiments.

IABLE 2. Test Conditions of Corrosion Experiments with JSS-A, PNL 76-68, and SRL-131, Which Are Quoted for Comparison with Modeling Results

\begin{tabular}{|c|c|c|c|c|c|}
\hline Glass & Leachant & $\begin{array}{c}\text { Temperature, } \\
{ }^{\circ} \mathrm{C}\end{array}$ & $\begin{array}{l}S / v, \\
m^{-1}\end{array}$ & $\begin{array}{c}\text { Flow Rate, } \\
\mathrm{mL} / \mathrm{d}\end{array}$ & $\begin{array}{c}\text { Max. Time, } \\
\text { day }\end{array}$ \\
\hline \multirow[t]{4}{*}{ JSS-A } & $\operatorname{DIW}^{(a)}$ & 90 & 10 & 0 & 365 \\
\hline & DIW & 90 & 10 & 2.9 & 180 \\
\hline & Groundwater & 90 & 10 & 0 & 90 \\
\hline & Si water & 90 & 10 & 0 & 90 \\
\hline \multirow[t]{2}{*}{ PNL $76-68$} & DIW & 90 & 10 & 0 & 365 \\
\hline & DIW & 90 & 10 & 14.0 & 180 \\
\hline \multirow[t]{5}{*}{ SRL-131 } & DIW & 90 & 10 & 0 & 1400 \\
\hline & Si water & 90 & 10 & 0 & 365 \\
\hline & Groundwater & 90 & 10 & 0 & 730 \\
\hline & DIW & 90 & 10 & 1.8 & 180 \\
\hline & DIW & 90 & 10 & 15.2 & 180 \\
\hline
\end{tabular}

(a) Deionized water. 
TABLE 3. Composition (mol/L) of Leachants Used in Quoted Leach Experiments

\begin{tabular}{|c|c|c|c|c|}
\hline \multirow[b]{2}{*}{ Component } & \multicolumn{2}{|c|}{ Synthetic Groundwater } & \multicolumn{2}{|c|}{ Si Water } \\
\hline & Basaltic ${ }^{(a)}$ & Granitic ${ }^{(b)}$ & $\mathrm{MCC}(\mathrm{c})$ & $\mathrm{JSS}^{(\mathrm{d})}$ \\
\hline $\mathrm{HCO}_{3}^{-}$ & 1.46 & 2.014 & 2.08 & 2.166 \\
\hline Si & 1.59 & 0.206 & 1.03 & 0.964 \\
\hline$S$ & -- & 0.1 & -- & -- \\
\hline C1 & 11.42 & 1.973 & 0.123 & $1.0^{(\mathrm{e})}$ \\
\hline $\mathrm{Ca}$ & 0.055 & 0.477 & -- & -- \\
\hline $\mathrm{Mg}$ & -- & 0.177 & -- & -- \\
\hline $\mathrm{K}$ & 0.35 & 0.1 & -- & -- \\
\hline $\mathrm{Na}$ & 14.65 & 2.836 & 2.08 & 1.304 \\
\hline $\mathrm{pH}$ & 9.7 & $8.0-8.2$ & 7.5 & 7.5 \\
\hline
\end{tabular}

(a) Strachan, Pederson, and Lokken (1985).

(b) Proposed by Allard (JSS 1984).

(c) MCC (1981).

(d) JSS (1984).

(e) Approximate.

The reported solution data include those from static tests with various leachant compositions and from dynamic tests. The data from static tests were all obtained using the MCC-1 Leach Test Method (MCC 1981) at temperatures of $40^{\circ} \mathrm{C}, 70^{\circ} \mathrm{C}$, and $90^{\circ} \mathrm{C}$. Dynamic leach data were obtained with the MCC-4 Low Flow Test Method (MCC 1981). In all cases, duplicate, and in many cases triplicate, specimens were run so that a measure of the experimental error was obtained.

\subsection{THERMO-KINETIC ANALYSES OF SOLUTION DATA}

The corrosion behavior of JSS-A, PNL 76-68, and SRL-131 has been carefully studied by large programs. The reported data bases can be used to derive the thermodynamic and kinetic parameters necessary for the modeling of the dissolution behavior of the various glasses. The subsequent application of the model to each set of corrosion data will demonstrate if this limited set of parameters, in combination with the model, can be used to provide a 
sufficient understanding of glass corrosion behavior and a basis for comparison of one glass with another. The parameters required for the model are as follows:

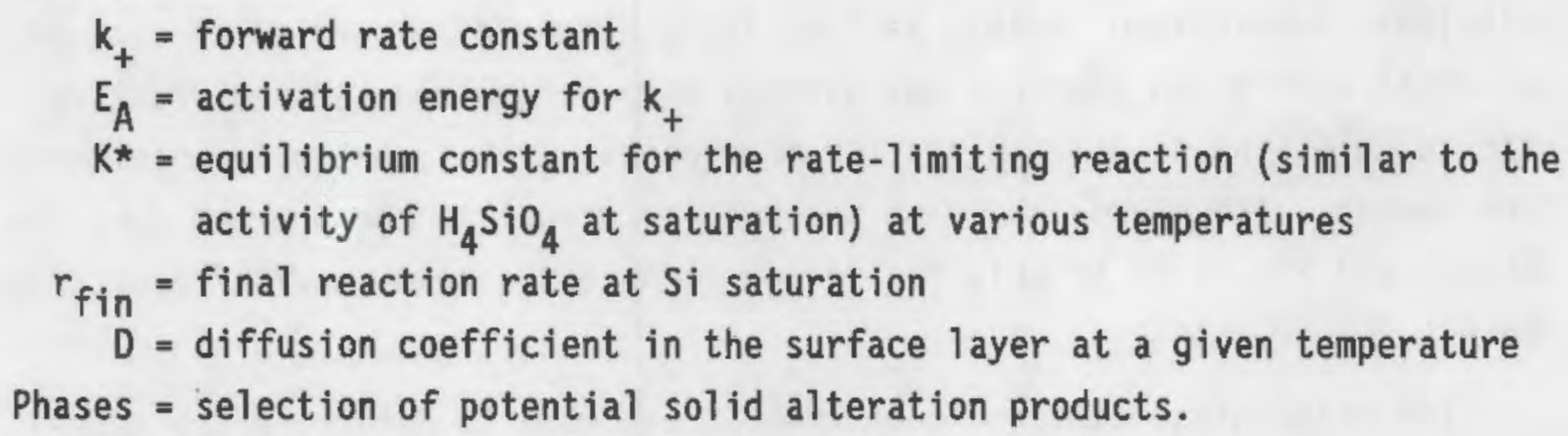

$D=$ diffusion coefficient in the surface layer at a given temperature Phases $=$ selection of potential solid alteration products.

Table 4 summarizes the values of the parameters in the model that need to be determined.

To check for supersaturation of potential alteration products and for silica saturation simulations, selected solution data were analyzed by chemical modeling of the solution data from the experiments.

\subsubsection{Data Analyses for Potential Alteration Products}

As discussed in Section 4.2, determining the formation sequence for glass alteration products is a difficult task, which requires some insight not only into the saturation state of the solution but also into the rate of formation. For reaction path calculations, the slow forming but very stable phases (i.e., goethite) must be excluded from the data base (see Section 4.1).

TABLE 4. Values of the Kinetic Parameters Used in the Model

\begin{tabular}{|c|c|c|c|}
\hline \multirow[b]{2}{*}{ Parameter } & \multicolumn{3}{|c|}{ Glass } \\
\hline & JSS-A & PNL 76-88 & $\underline{\text { SRL-131 }}$ \\
\hline Temp., ${ }^{\circ} \mathrm{C}$ & 90 & 90 & 90 \\
\hline$k_{+}\left[g /\left(m^{2} \cdot d\right)\right]$ & 1.5 & 1.8 & 3.0 \\
\hline $\log K^{*}$ & -2.9341 & -2.715 & -2.915 \\
\hline $\begin{array}{l}r_{f i n}\left[g /\left(m^{2} \cdot d\right)\right] \\
D\left[\mathrm{~cm}^{2} / s\right]:\end{array}$ & $\begin{array}{l}0.0025 \\
10^{-9}\end{array}$ & $\begin{array}{c}0.0075 \\
10^{-7}\end{array}$ & $\begin{array}{l}0.033 \\
10^{-8}\end{array}$ \\
\hline$E_{A}[k J / m o l]$ & 105 & 75 & -- \\
\hline
\end{tabular}


Because of the limited knowledge about the formation rate of solid alteration products, and considering the difficulties of analyzing amorphous alteration products by solid-state techniques, the saturation state of the solutions is described in this section for a number of minerals. A list of potential alteration products has already been determined for the reaction path calculations of JSS-A glass (Grambow et al. 1986a), but some uncertainties remain. Therefore, it seems worthwhile to analyze the present data for SRL-131 and PNL 76-68 in this regard and compare the results with results for JSS-A.

The geochemical computer code PHREEQE was used to determine the saturation state of various minerals from the reported solution analyses. This saturation state was then used as a guideline in the selection of potential alteration products. If solutions were found to always be supersaturated with respect to a given phase, then that phase was treated as a slow forming solid. If, on the other hand, the solution was always far below saturation it could not be ruled out that such a phase might form under more appropriate conditions. However, to simplify the data base, such phases may be omitted without affecting the calculations.

Accurate determination of the saturation states depends on a complete solution analysis, and although the data sets are thorough, anion data generally are lacking. Limited anion data exist for carbonate for the 1-year data point at $90^{\circ} \mathrm{C}$ (Strachan 1984). For the synthetic groundwater, the anion data come from the solution makeup and not from analyses. These missing data make it difficult to use complex starting solutions in the model because the $\mathrm{pH}$ is usually calculated assuming that the solution is charge balanced; e.g., the number of equivalents of anions equals the number of equivalents of cations. Illustrative of the problem is the use of silicate water (MCC 1981), where, after the $\mathrm{NaHCO}_{3}$ and $\mathrm{SiO}_{2} \cdot \times \mathrm{H}_{2} \mathrm{O}$ have been added to the water, the $\mathrm{pH}$ is adjusted to 7.5 using $\mathrm{HCl}$. Since the amount of $\mathrm{HCl}$ added depends on the source of the chemicals used, the quantity added varies (Table 3 ). There is no requirement that the amount of $\mathrm{HCl}$ be reported. In the case of JSS-A, Na $\mathrm{SiO}_{3}$ instead of $\mathrm{SiO}_{2} \cdot \mathrm{HH}_{2} \mathrm{O}$ was used as the source of $\mathrm{Si}$ for the makeup of silicate water, with a concomitant increase in the required quantity of $\mathrm{HCl}$. 
To estimate the amount of $\mathrm{HCl}$ added, the nominal solution composition of silicate water with $\mathrm{CO}_{3}^{2-}$ but without $\mathrm{Cl}^{-}$was used as input to the PHREEQE program to calculate the charge imbalance between anions and cations. The amount of anions needed for charge balance was attributed to the missing $\mathrm{Cl}^{-}$. In a subsequent $\mathrm{Cl}^{-}$analysis, the calculated value deviated by less than a factor of 2 from the measured value. Therefore, the calculated quantity of $\mathrm{Cl}^{-}$was used for all silicate water solutions for which $\mathrm{Cl}^{-}$had not been measured. The same approach was taken for modeling the initial solution composition of synthetic groundwater (Allard water, Table 3). Charge imbalance is generally found when modeling solution data from glass dissolution. This may be a result of overall analytical error, the lack of anion or cation data, or the use of room-temperature $\mathrm{pH}$ data.

In general, the relative analytical error of the major inorganic solution constituents is on the order of $10 \%$ to $20 \%$. Since no certified standards exist for this type of testing, the absolute error cannot be estimated. The analytical error associated with the $\mathrm{pH}$ measurement should be about 0.1 units within $a \mathrm{lab}$ and 0.5 units between labs (Johnston and Daniel 1982), but the room-temperature $\mathrm{pH}$ may deviate from the test-temperature $\mathrm{pH}$ by as much as $1 \mathrm{pH}$ unit. The solutions were assumed to be in equilibrium with the atmospheric partial pressure of $\mathrm{CO}_{2}(\mathrm{~g})$, except in those cases where the specimens were tested under $\mathrm{CO}_{2}$-free conditions. To attain charge balance for each leachate, the assumption was made that $\mathrm{pH}$ was not correct. Therefore, a large analytical error for the cations in the leachate from any given sample of glass would lead to an abnormally high or low $\mathrm{pH}$ relative to the other samples in the series.

The results of chemical modeling of the solutions are shown in Figures 7 through 10. The logarithm of the saturation index, IAP/K, is plotted versus the reaction progress variable. A value of zero for $\log (I A P / K)$ denotes saturation; i.e., IAP for the respective ideal mineral equals its solubility product, $K$. Positive values denote supersaturation and negative subsaturation. The reaction progress value in units of $\mathrm{mg}$ of glass dissolved per $\mathrm{cm}^{3}$ of solution is calculated by the product of the normalized elemental mass loss, NL, of a soluble element such as B and the $S / \mathrm{V}$. 


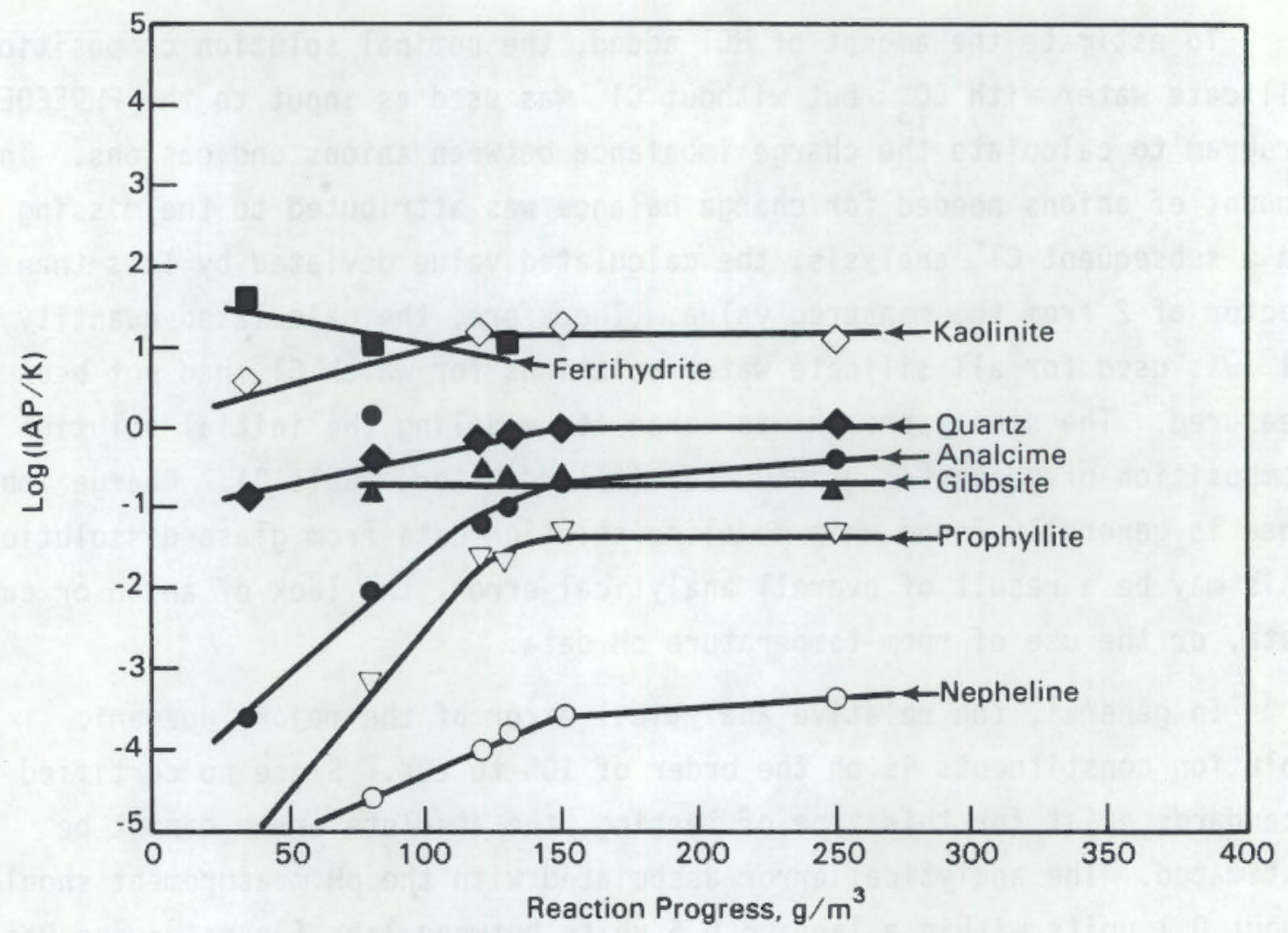

FIGURE 7. Calculated Saturation Indices for JSS-A in Deionized Water at $90^{\circ} \mathrm{C}$ from Reported Solution Analyses

The general result of the calculations is that the solutions are supersaturated with respect to some minerals, whereas other minerals remain below saturation throughout the progress of the reaction. The dependence of the saturation states on reaction progress gives a somewhat complicated picture, and in many cases it is not obvious whether some level of saturation eventually will be reached. However, the slopes of all curves are interrelated via the solution composition and the stoichiometry of the phases.

For JSS-A, Figures 7 through 9 show the results of the reaction progress calculations for dissolution in deionized water, synthetic groundwater, and silicate water. Ferrihydrite and kaolinite are usually 1 to 2 orders of magnitude oversaturated. The slopes of the curves for the Al-silicate phases are correlated with the silica-to-aluminum ratio in the solid and the degree of quartz and gibbsite saturation. For deionized water (Figure 7), the saturation state of quartz seems to remain constant (close to a value of zero $=$ 


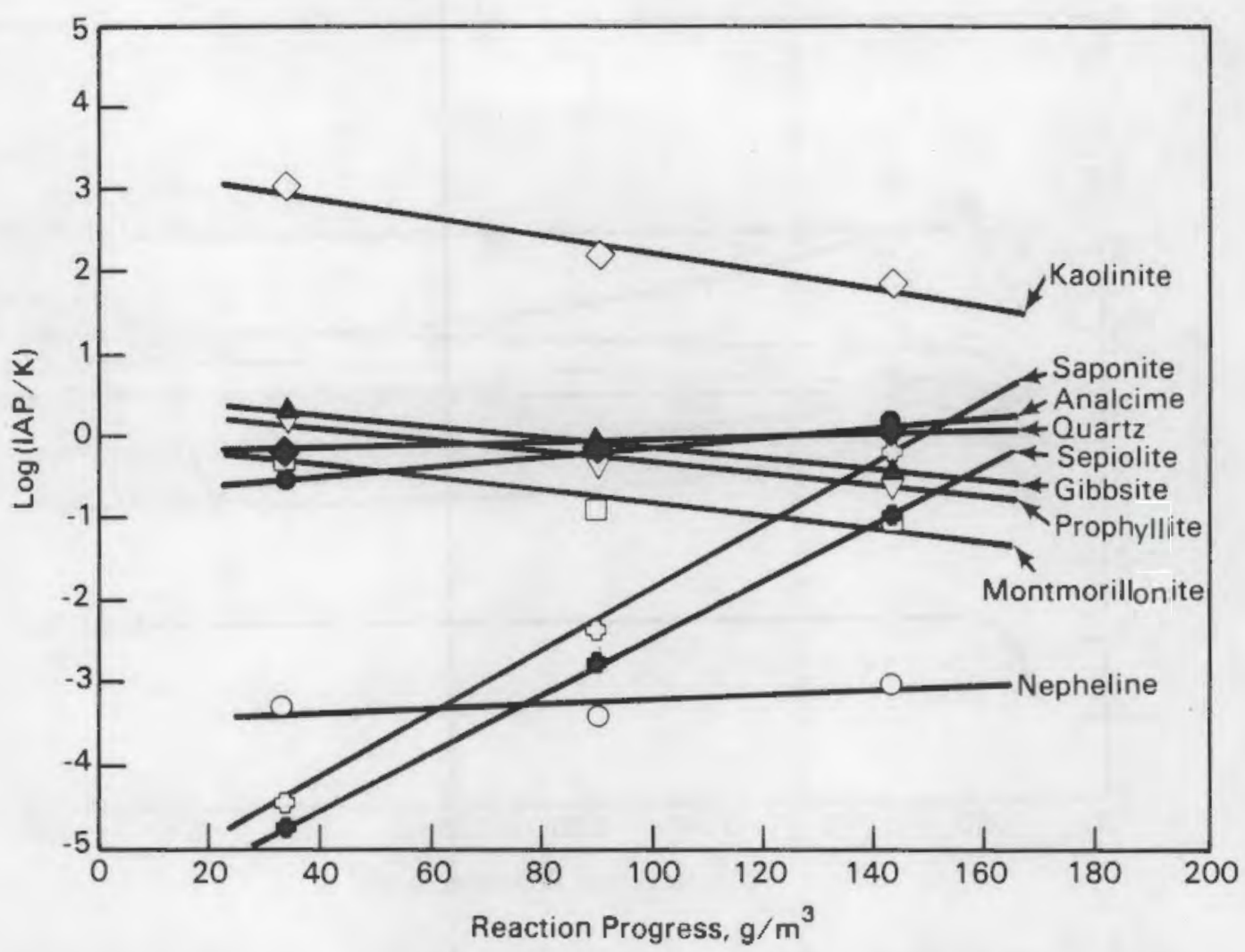

FIGURE 8. Calculated Saturation Indices for JSS-A in Synthetic Groundwater at $90^{\circ} \mathrm{C}$ from Reported Solution Analyses

saturation) after a reaction progress of about $150 \mathrm{mg} / \mathrm{L}$. Above this reaction progress, the curves for the A1-silicates and for gibbsite remain constant. At lower reaction progress, the slopes of the $1: 1$ ( $\mathrm{Si}: \mathrm{Al}$ ) Al-silicates (kaolinite, nepheline) are higher than for the 2:1 phases pyrophyllite and analcime.

For synthetic groundwater (Figure 8), quartz is nearly saturated at all stages of the reaction, while the degree of gibbsite saturation decreases from slightly oversaturated to slightly undersaturated values. As long as the Al-silicates contain little or no Na, 1:1 and 2:1 Al-silicates (kaolinite, pyrophyllite, and montmorillonite) show a similar decrease in saturation indices with reaction progress, whereas, due to alkali leaching, the saturation indices increase for $\mathrm{Na}$-containing solids. The rise in $\mathrm{pH}$ is responsible for the sharp increase in IAP/K for the Mg-silicate phases (sepiolite and saponite) since the glass does not contain $\mathrm{Mg}$, and silica remains constant. 


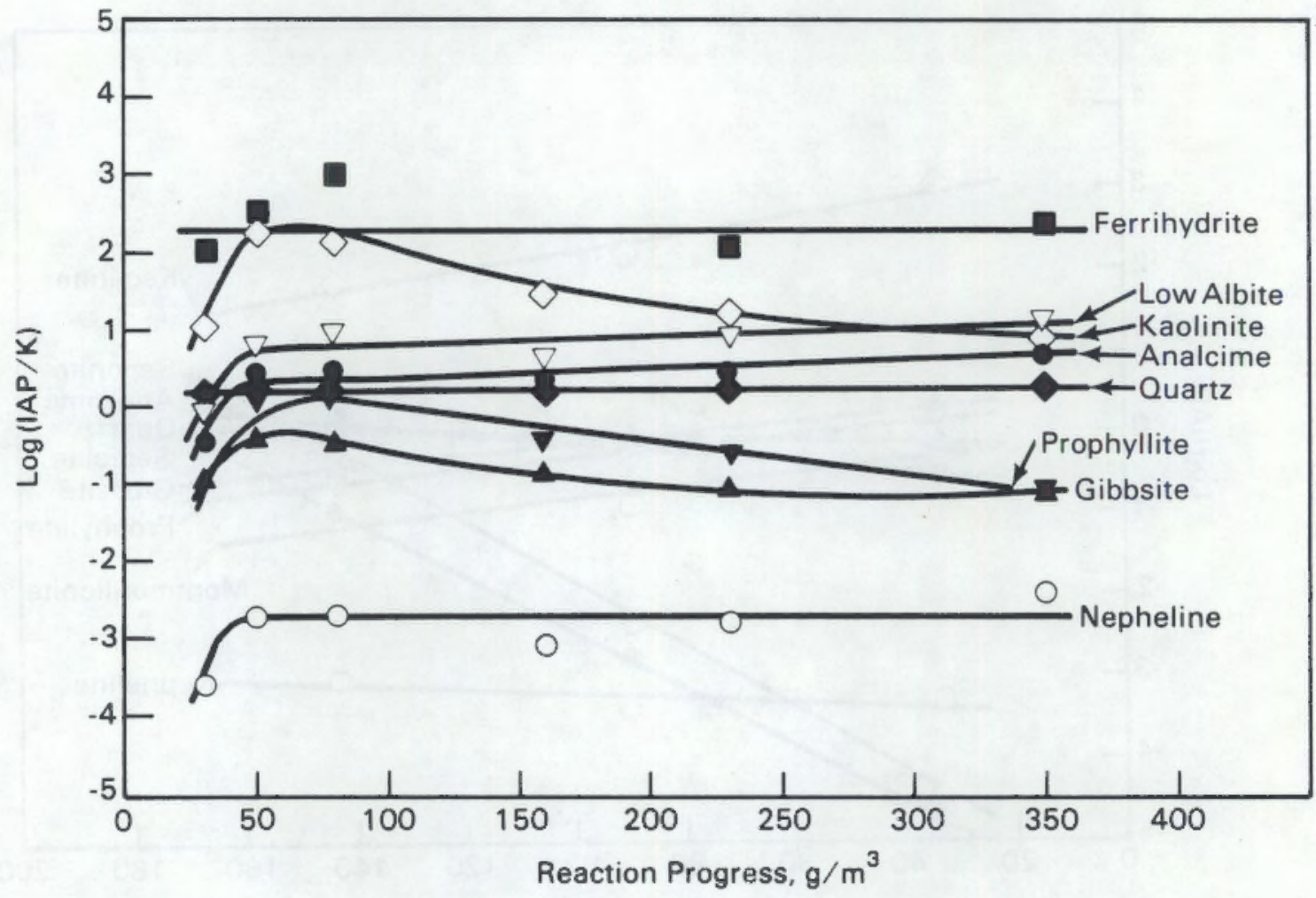

FIGURE 9. Calculated Saturation Indices for JSS-A in Silicate Water at $90^{\circ} \mathrm{C}$ from Reported Solution Analyses

For silicate water (Figure 9), the IAP/K values are similarly constrained as for synthetic groundwater. The maximum value in IAP/K for many phases at $50 \mathrm{mg} / \mathrm{L}$ is a result of abnormally high Al concentrations in the 3-day solutions. These high concentrations indicate either real supersaturation of phases like gibbsite or the presence of Al-hydroxide colloids.

In all cases, at short reaction progress the saturation index is higher for gibbsite than for analcime because the $\mathrm{pH}$ and the Si concentration are low. However, saturation indices are higher for analcime at larger reaction progress values because of release of the alkali ions. Using gibbsite and analcime for solubility control in the reaction path model seems promising; nevertheless, it should be kept in mind that, for example in silicate water, the long-term solutions are oversaturated with respect to an ideal analcime phase ( $\log \mathrm{IAP} / K=0.6$, i.e., factor of 4 oversaturated). Consequently, the use of ideal analcime in the reaction path model will yield computed $A 1$ concentrations that will be too low. 


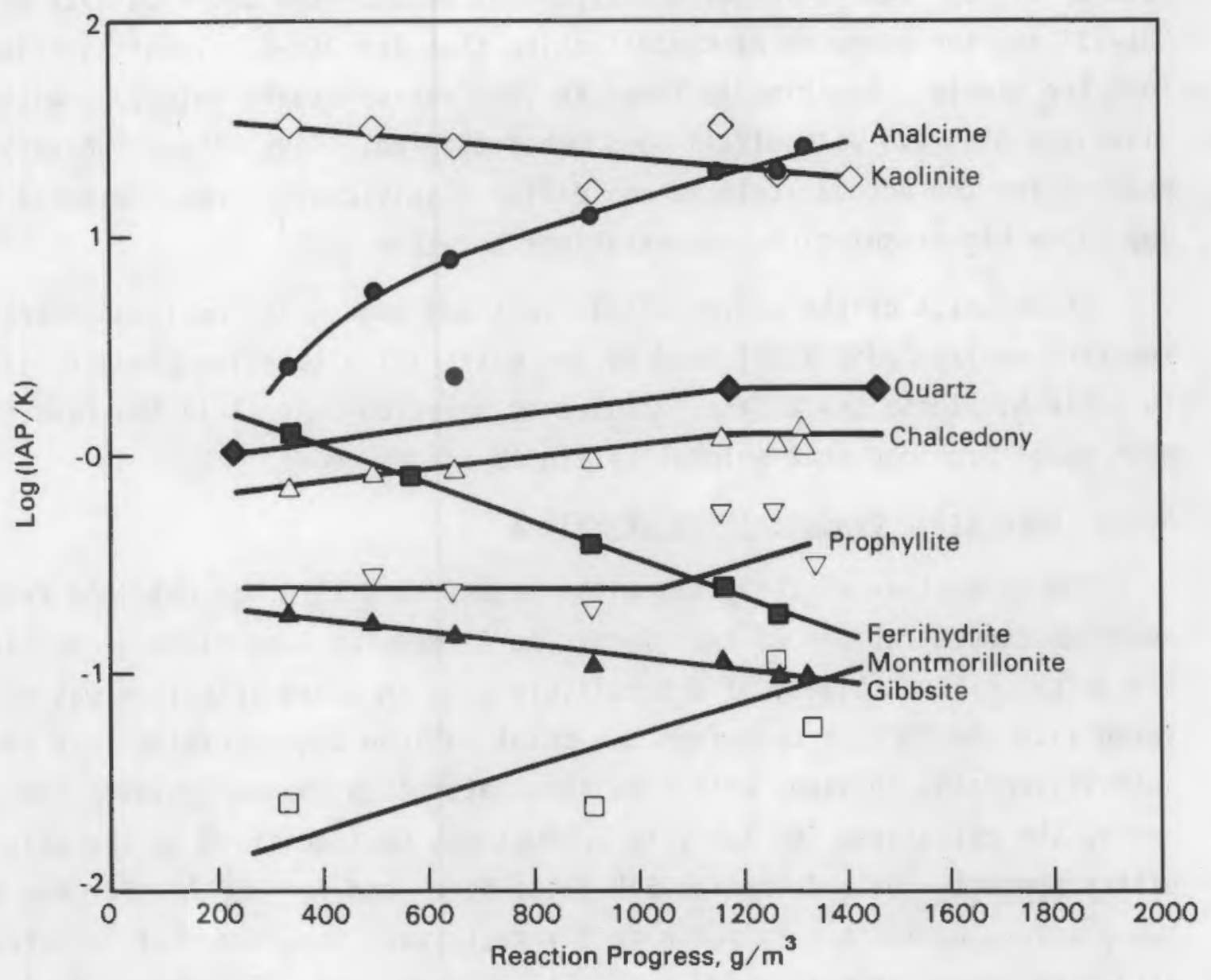

FIGURE 10. Calculated Solution Indices for SRL-131 in Deionized Water at $90^{\circ} \mathrm{C}$ from Reported Solution Analyses

For SRL-131 leached in deionized water, Figure 10 shows the results of solution modeling. The saturation states for kaolinite (supersaturated by 1 to 2 orders of magnitude) and for gibbsite (slightly undersaturated) are similar to those found for JSS-A. The solutions are about a factor of 2 more oversaturated with respect to quartz than the JSS-A solutions. Ferrihydrite deviates in all solutions by less than a factor of 10 from saturation. The leachants are much more oversaturated (by as much as a factor of 20) with respect to analcime than the solution from JSS-A. Despite this supersaturation, analcime must be used in the reaction path model because a Cs-containing analcime was observed as an alteration product on SRL-131 glass in another study (MCC 1984). However, the use of ideal analcime in the reaction 
path model may lead to larger discrepancies between the solution data of SRL-131 and the computed Al concentration than for JSS-A. Ideal analcime may form too slowly. Analcime is known to form various solid solutions with dissolved $\mathrm{SiO}_{2}$ and with alkali ions other than $\mathrm{Na}$. Thus, the solubility product for the actual analcime may differ significantly from the ideal and may allow higher solution concentrations than the ideal.

The results of the above calculations and some additional considerations reported earlier (JSS 1986) lead to the potential alteration products listed in Table 5. These phases are included as solution control in the reaction path model provided that solubility limits are exceeded.

\subsubsection{Saturation Concentration of Silica}

The saturation of the glass with respect to silica was obtained from solution concentrations of experiments performed for long times or at high $S / V$ values. The activity of orthosilicic acid in these solutions was calculated with the PHREEQE code from the total silicon concentration. If that activity remains constant with time then saturation may be achieved and, hence, the calculated ion activity product may be identified as the solubility product. Data from high $S / V$ tests were used for JSS-A. For the other two glasses, no leach data for high $S / V$ tests were reported, but long-term data from experiments at a $S / V=10 \mathrm{~m}^{-1}$ could be used. Two-year data from SRL-131 and 1-year data from PNL 76-68 were used to derive a preliminary silica saturation concentration for modeling. The experience with 1-year data from JSS-A has shown, however, that this procedure may lead to saturation concentrations that are as much as a factor of 2 too low (Grambow et al. 1986a). The results for the various glasses are contained in Table 5 and expressed as the logarithm of an equilibrium constant for the reaction $\mathrm{SiO}_{2}+2 \mathrm{H}_{2} \mathrm{O}=\mathrm{H}_{4} \mathrm{SiO}_{4}$.

\subsubsection{Rate Constants}

Before the glass reaction can be modeled, the forward rate of reaction must be determined by one of two methods. The first is to calculate the rate from either short-term data or from Soxhlet data. As long as the leachates are far from saturation and $\mathrm{H}_{4} \mathrm{SiO}_{4}$ diffusion can be neglected, this method 
TABLE 5. Set of Alteration Products Used in GLASSOL and PHREEQE to Model the Corrosion Behavior of JSS-A, PNL 76-68, and SRL-131.

Element

B, Li, Cs

$\mathrm{Na}$

$\mathrm{Si}$

Al

$\mathrm{Fe}$

Mo

$\mathrm{Nd}$

$\mathrm{Ca}$

$\mathrm{Zn}$

$\mathrm{Sr}$

$\mathrm{Mn}$

$P$

$\mathrm{Mg}$

$\mathrm{Ba}$

U

$\mathrm{Zr}$

none

analcime $\left[\mathrm{Na}\left(\mathrm{AlSi}_{2} \mathrm{O}_{6}\right) \cdot \mathrm{H}_{2} \mathrm{O}\right]$

$\mathrm{SiO}_{2}\left(\log \mathrm{K}_{\mathrm{Si}}=-2.935\right)$

Phase(s)

gibbsite $\left(\mathrm{Al}(\mathrm{OH})_{3}\right)$, analcime, montmorillonite

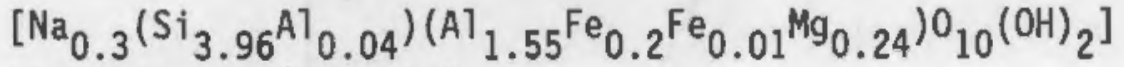

ferrihydrite $\left[\mathrm{Fe}(\mathrm{OH})_{3}\right]$

$\mathrm{BaMoO}_{4}, \mathrm{CaMoO}_{4}$

$\mathrm{Nd}(\mathrm{OH})_{3}$

calcite $\left[\mathrm{CaCO}_{3}\right], \mathrm{CaO} \cdot \mathrm{SiO}_{2} \cdot \mathrm{H}_{2} \mathrm{O}, \mathrm{CaO} \cdot \mathrm{SiO}_{2}$

Ca-montmorillonite $\left[\mathrm{Ca}_{0.17} \mathrm{Si}_{3.67} \mathrm{Al}_{2.33}{ }_{2}{ }_{2}(\mathrm{OH})_{2}\right]$

Zn-chamosite

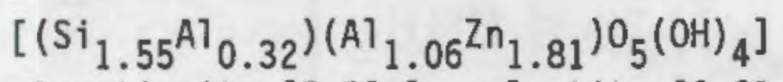

strontianite $\left[\mathrm{SrCO}_{3}\right]$, celestite $\left[\mathrm{SrSO}_{4}\right]$

rhodochrosite $\left[\mathrm{MnCO}_{3}\right]$, pyrolusite $\left[\mathrm{b}-\mathrm{MnO}_{2}\right]$

hydroxyapatite $\left[\mathrm{Ca}_{5}\left(\mathrm{PO}_{4}\right)_{3} \mathrm{OH}\right]$, strengite

$\left[\mathrm{FePO}_{4} \cdot 2 \mathrm{H}_{2} \mathrm{O}\right]$, vivianite $\left[\mathrm{Fe}_{3}\left(\mathrm{PO}_{4}\right)_{2} \cdot 8 \mathrm{H}_{2} \mathrm{O}\right)$

sepiolite $\left[\mathrm{Mg}_{2} \mathrm{Si}_{3} \mathrm{O}_{6}(\mathrm{OH})_{4}\right]$, brucite $\left[\mathrm{Mg}(\mathrm{OH})_{2}\right]$,

artinite $\left[\mathrm{MgCO}_{3}\right]$

barite $\left[\mathrm{BaSO}_{4}\right]$

schoepite $\left[\mathrm{UO}_{2}(\mathrm{OH})_{2} \cdot \mathrm{H}_{2} \mathrm{O}\right]$

$\mathrm{ZrSiO}_{4}$

works wel1. A second method is to plot the rate as a function of the activity of $\mathrm{H}_{4} \mathrm{SiO}_{4}$. According to Equation (1) in Section 4.1, this method should lead to a straight line with intercepts of $k_{+}$on the $y$-axis and a $\left[\mathrm{H}_{4} \mathrm{SiO}_{4}\right.$ (sat)] on the $\mathrm{x}$-axis. An example of such a plot is shown in Figure 11 for JSS-A at $90^{\circ} \mathrm{C}$ in deionized water (Grambow et al. 1986a). From this plot $k_{+}=1.5 \mathrm{~g} /\left(\mathrm{m}^{2} \cdot d\right)$ and the saturation concentration for the glass may be obtained. For the other glasses in this study, the forward rate was obtained using the early time data. The results for various glasses are included in Table 4. 


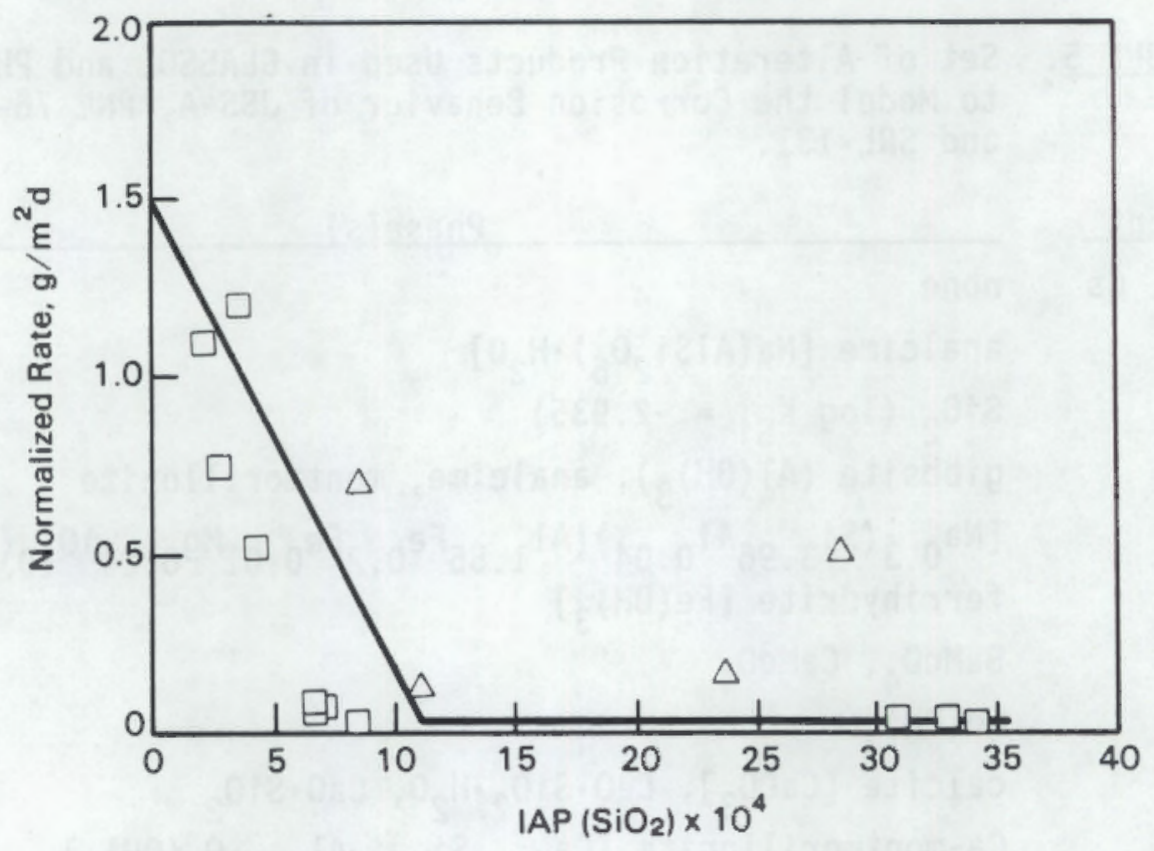

FIGURE 11. Dependence of Leach Rates on the Ion Activity Product IAPSi0, of Silica ("Silica Concentration") in Leachates (Grambow 1987)

The final rate of reaction, $r_{f i n}$, is more difficult to measure than the forward rate because it is about a factor of 100 to 1000 lower. Leach tests with glass powders usually are required for an accurate determination (JSS 1987). Tentatively, final rates have been determined for SRL-131 glass using results from the 4-year test by Wicks et al. (1986), as a linear long-term rate seems to be reached after about a year of reaction. For JSS-A the long-term rate was reported by Grambow et al. (1986a). For PNL 76-68 the long-term rate was calculated from the data of Shade and Strachan (1986). All long-term rates used in modeling were summarized in Table 4.

The diffusion coefficients were determined by trial-and-error fitting of the model to the data from leach experiments in flowing solutions. An example of such a fitting was given in Figure 2. The resulting diffusion coefficients were included in Table 4. 


\subsection{COMPARISON OF MODEL AND EXPERIMENT}

After the thermodynamic and kinetic parameters were derived from the analysis of the solution data, the corrosion behavior of each glass was modeled for test conditions and compared with the observations. The kinetic parameters used for modeling were given in Table 4 , and the list of potentially precipitating phases was given in Table 5 . The test conditions for the various glasses were given in Table 2. In the following sections, the modeling results for each glass are discussed and compared with the solution data.

\subsubsection{JSS-A and ABS-118}

The parameters used for JSS-A (Table 4) are a result of the analysis of much more data (JSS 1987) than are reported in this document and the constraint that the same set of parameters should be used when applying the model to results from all the various types of experiments. These experiments include the use of solutions of different composition and the presence of clays and iron corrosion products. Most of these data are not discussed here. A detailed documentation is given by the JSS (1987).

The dissolution of JSS-A was first studied in deionized water at $90^{\circ} \mathrm{C}$. Data have now been collected for time periods extending up to 365 days. The data and the calculated curves for JSS-A in deionized water are shown in Figure 12. The fit to the data by the calculated curves is within the observed scatter of the data, with the possible exception of the early Al data. This discrepancy for Al may be a result of sorption onto the surface layer during the early part of the experiment or an incorrectly assigned phase. After long times, however, the calculation appears to converge on the observed data.

In Figure 13, the modeling results are shown for JSS-A dissolved in a synthetic groundwater (Allard water). The composition of the groundwater was given in Table 3. The corresponding data are shown for silicate water in Figure 14. Although the data set is 1 imited and the data are only taken over a short period of time, the calculated lines are in reasonable agreement with the observations. A more extensive data set would be needed to demonstrate that the agreement is good to very long periods of time. 


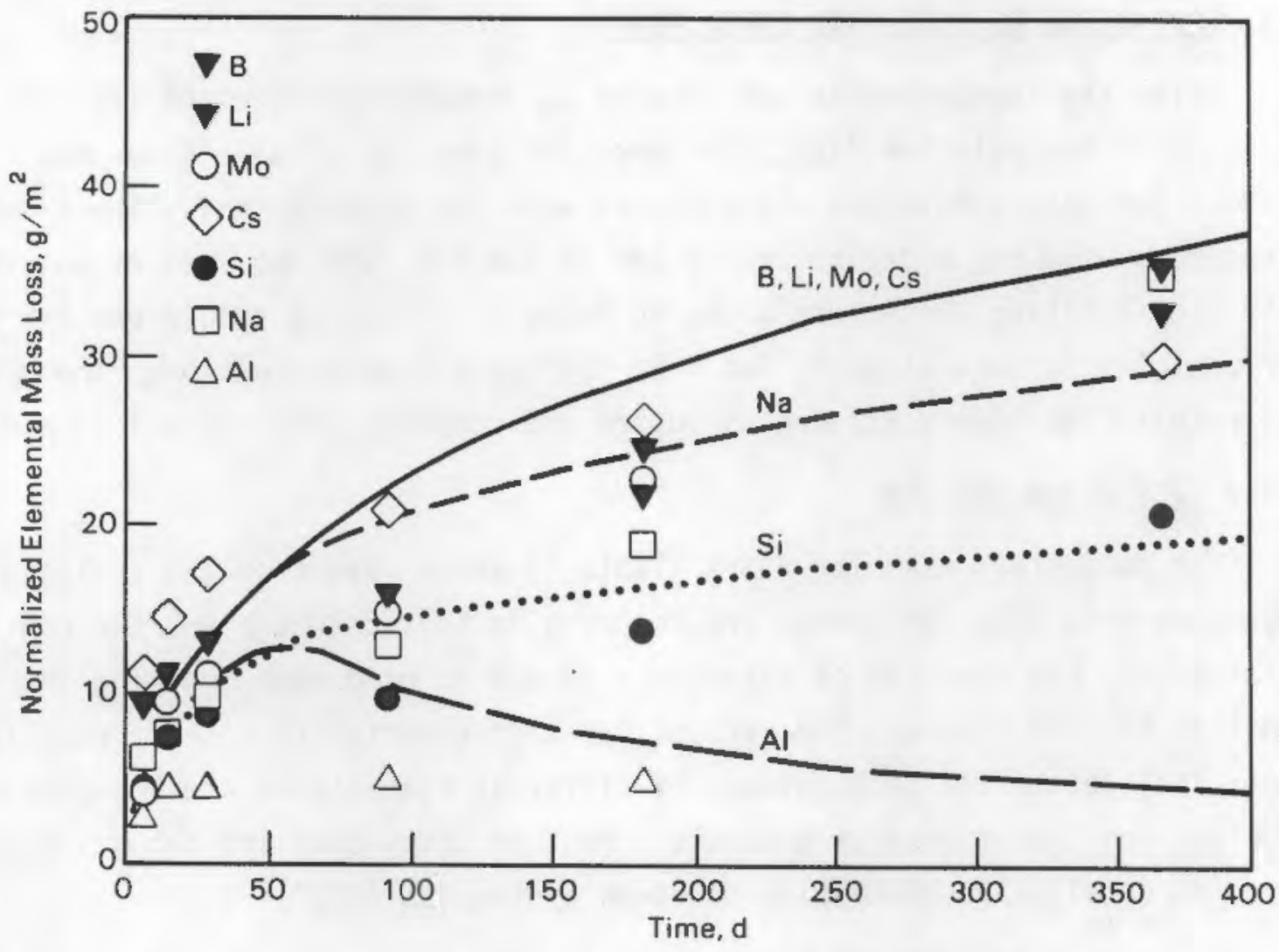

FIGURE 12. Comparison of Calculated and Observed Data for JSS-A in Deionized Water at $90^{\circ} \mathrm{C}$, Static Conditions, and $S / V=10 \mathrm{~m}^{-1}$

Figure 15 summarizes the results from the calculations of the $\mathrm{pH}$ of the solutions at $90^{\circ} \mathrm{C}$. No data are plotted since the $\mathrm{pH}$ is measured at room temperature. These plots are shown only to indicate the predicted trend in the $\mathrm{pH}$ as a function of time over the period of the experiment.

The application of the model to flow tests with the ABS-118 is shown in Figure 16. The reaction path model and the kinetic parameter are the same as those used for the corrosion of JSS-A in static deionized water. The calculated $B$ concentration agrees with the measured values. Similar agreement is obtained for Si data (not shown). The maximum in the curve is achieved when the release from the glass is balanced by the removal of dissolved material by the flow and when the surface layers are thin. As the surface layer becomes thicker, the release rate decreases along with the solution concentration. 


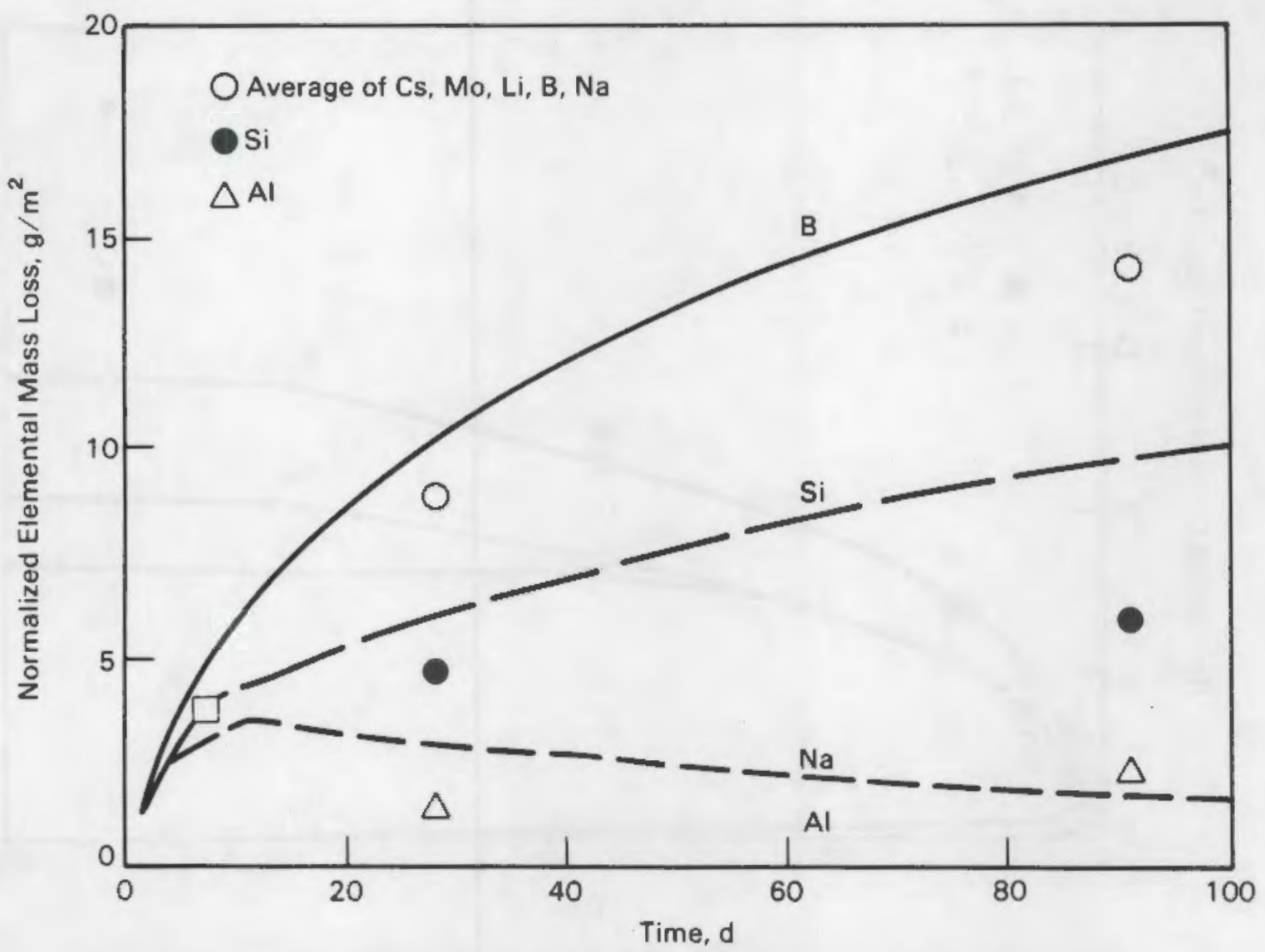

FIGURE 13. Comparison of Calculated and Observed Data for JSS-A in Synthetic Groundwater at $90^{\circ} \mathrm{C}$, Static Conditions, and $S / V=10 \mathrm{~m}^{-1}$

\subsubsection{PNL 76-68}

Agreement between the model calculations and the observed data for the dissolution of PNL 76-68 in deionized water at $90^{\circ} \mathrm{C}$ in a standard MCC -1 Static Leach Test Method (MCC 1981) is shown in Figure 17. The agreement between the calculated $\mathrm{B}, \mathrm{Na}$, and $\mathrm{Si}$ is within $20 \%$. The concentrations of the minor constituents, such as $A 1$ and $\mathrm{Fe}$, are generally below the detection limits in the leachates from glass dissolution. The calculated $\mathrm{pH}$ values are shown in Figure 18.

Data from the MCC-4 Low Flow Test Method are plotted in Figure 19 together with the calculated curves. The same parameters were used for the calculations as those used to generate the static data (Figure 17). The long flat portion of the calculated curve is an artifact of the way the curve was 


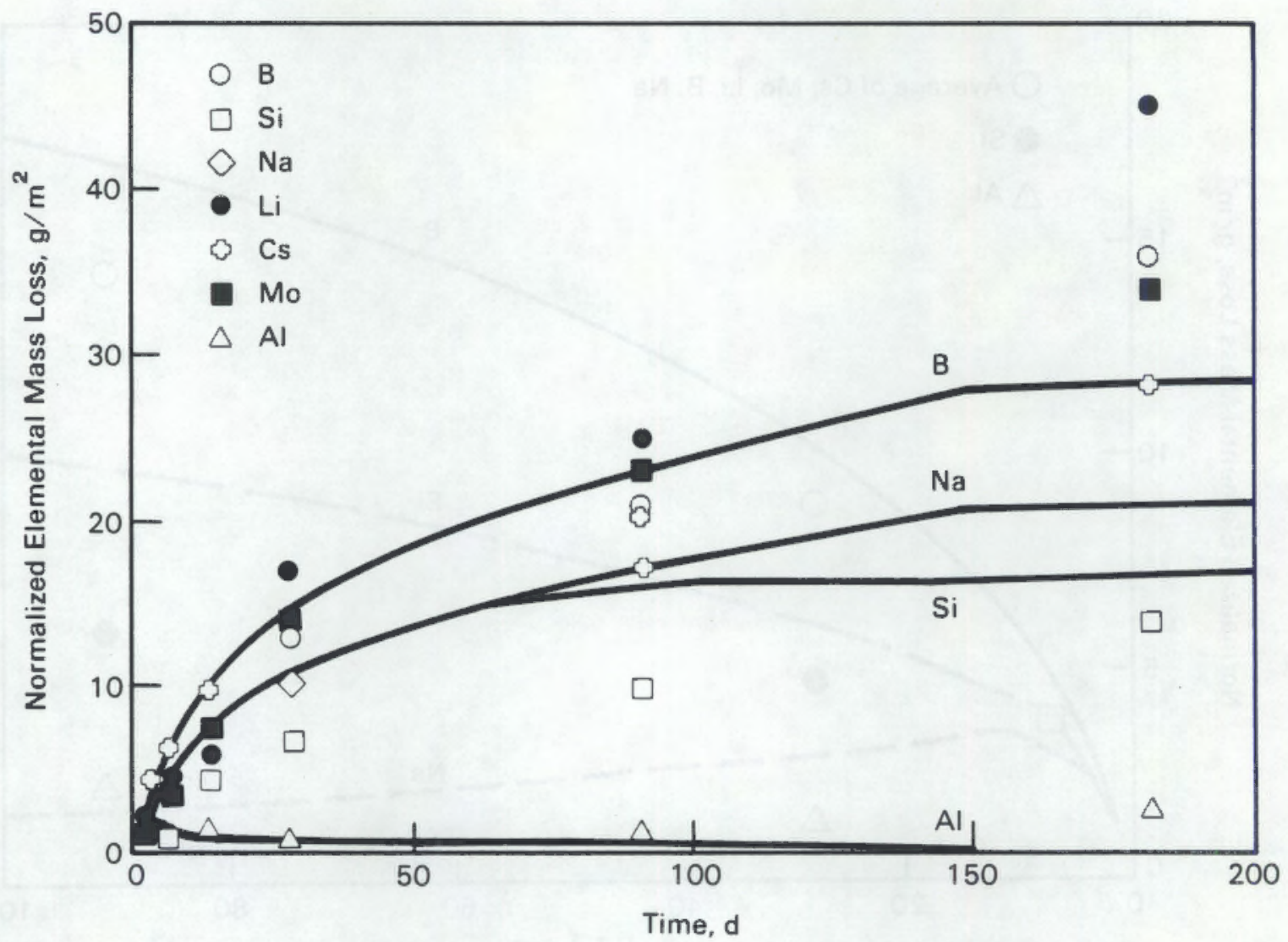

FIGURE 14. Comparison of Calculated and Observed Data for JSS-A in Silicate $]_{\text {Water }}$ at $90^{\circ} \mathrm{C}$, Static Conditions, and $S / V=10 \mathrm{~m}^{-1}$ (JSS 1987)

calculated. Increasing the detail of the calculations would decrease the width of the flat area, sharpening the peak, although the curve would still pass through the same points at either end of the flat portion.

\section{2 .3 SRL-131}

For the corrosion of SRL-131 in deionized water at $90^{\circ} \mathrm{C}$, the model ing results were compared with static test data obtained by two independent laboratories (Strachan, Pederson, and Lokken 1985; Wicks et a1. 1986). For B and $\mathrm{Si}$, the two data sets are in remarkable agreement for the time periods over which they overlap (Figures 20 and 21). Although there is considerable scatter in the data (all data points were included), there is reasonable agreement between the calculated and the observed values of these elements. For $\mathrm{Na}$, the data sets do not agree. 


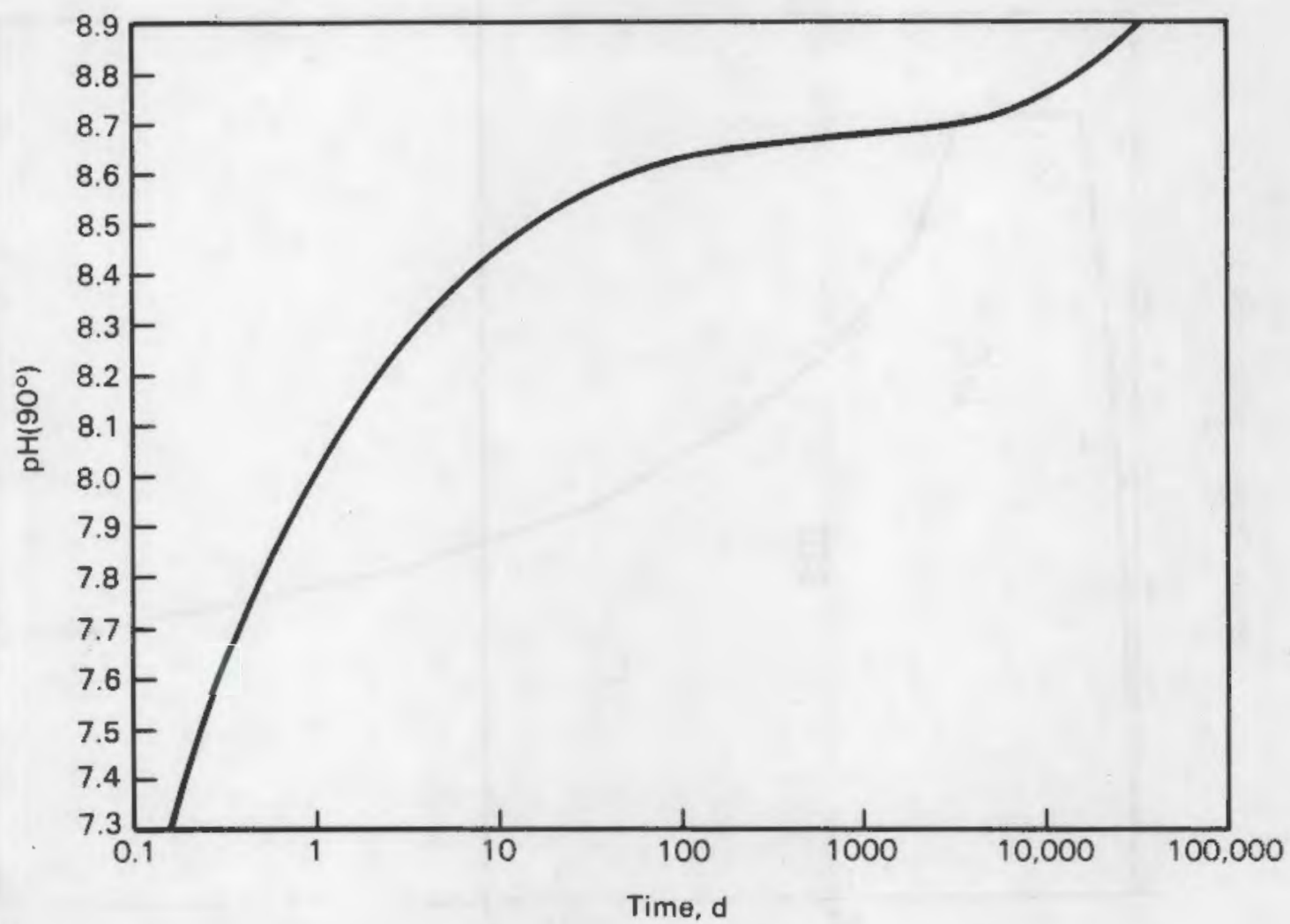

FIGURE 15. Calculated $\mathrm{pH}\left(90^{\circ} \mathrm{C}\right)$ as a Function of Time for the Dissolution of JSS-A in Deionized Water

This study relied more on the data from Strachan, Pederson, and Lokken (1985) (Figure 20) because the variability in these data was less than in those from Wicks et al. (1986) (Figure 21). It should be noted that the higher release of $\mathrm{Na}$ than $\mathrm{B}$ in the experiments performed by Wicks et al. does not point to a different release mechanism (i.e., alkali diffusion) because during the test period of 4 years the ratio of the release of $\mathrm{Na}$ to that of $B$ remained constant at $1.43 \pm 0.2$. Hence, the release of both ions is governed by matrix dissolution.

It is also interesting to note that if only 2-year data from Strachan, Pederson, and Lokken (1985) would have been modeled, a much lower final rate would have been suggested. This points to the need for either very long-term tests or accelerated tests in which high $(S \cdot t) / V$ values are used.

For corrosion tests in deionized water with solution flow rates of 1.8 and $15.2 \mathrm{~mL} / \mathrm{d}$, the reported solution concentrations of $B$ and the modeling 


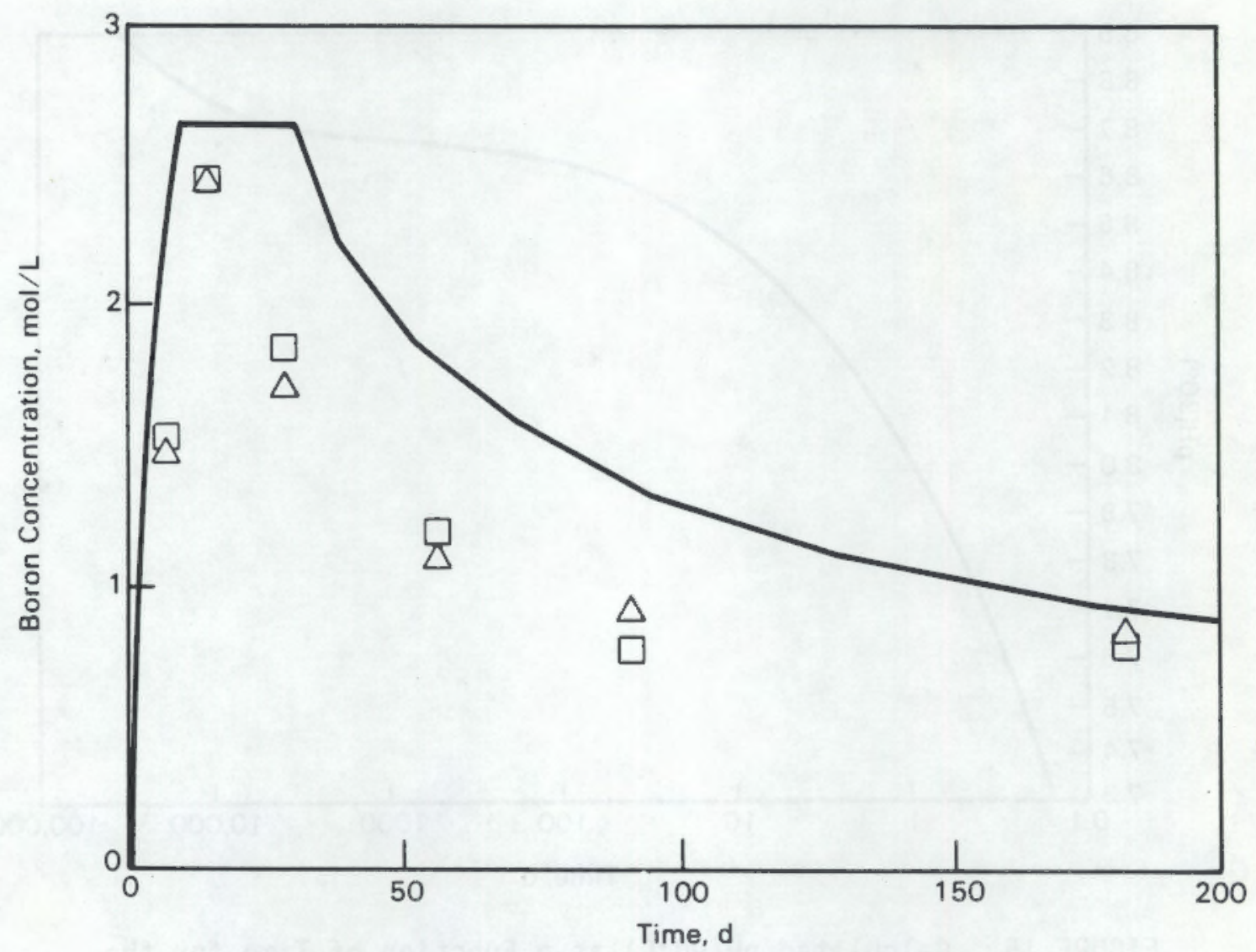

FIGURE 16. Comparison of Calculated and Observed Data for ABS-118 in Deionized Water at $90^{\circ}$; Flow Rate $=1.8 \mathrm{~mL} / \mathrm{d}$

results are plotted in Figure 22 as a function of time. The model parameters are the same as those used to generate the static test data shown in Figure 21. For comparison, the results of static tests are included in Figure 22. There is excellent agreement between the calculated curves and the measured solution concentrations. It should be noted that the peak in the calculated curves and in the solution data moves to longer times and becomes broader as the flow rate is decreased.

Figure 23 illustrates the agreement between the observed solution concentrations and those calculated for the reaction of SRL-131 with silicate water. The agreement is again within $20 \%$, except for A1. There is about a factor of 2 decrease in the dissolution of SRL-131 in silicate water relative to that in deionized water over a period of 1 year. The decreased 


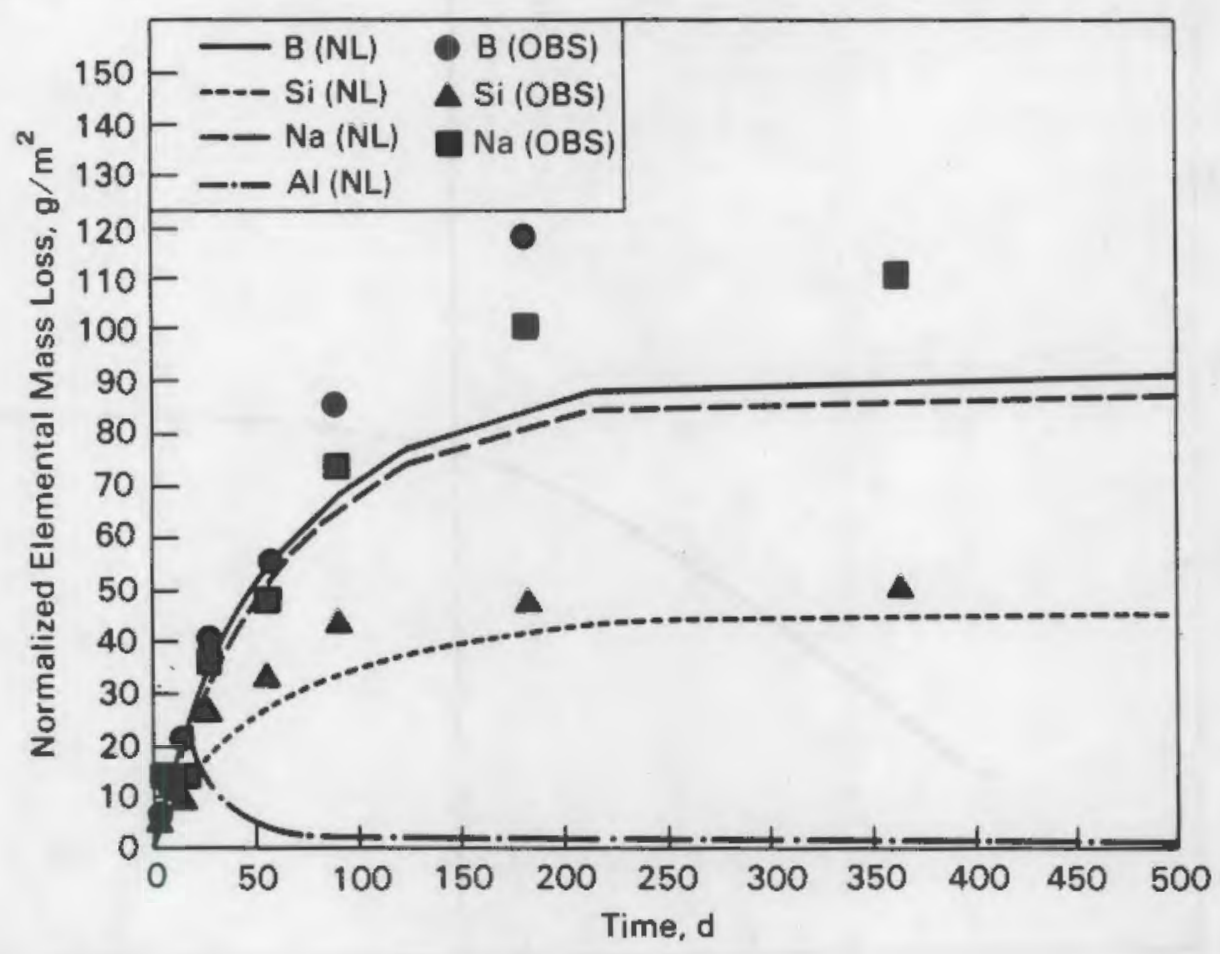

FIGURE 17. Comparison of Calculated and observed Data for PNL 76-68 in Deionized Water at $90^{\circ} \mathrm{C}$, Static Conditions, and $S / V=10 \mathrm{~m}^{-1}$

dissolution in a given time period is caused by the silica concentration in the silicate water, while the initial $\mathrm{pH}$ is about the same as that of deionized water.

The results of the leach tests using synthetic groundwater are shown in Figure 24 for a test duration of up to 720 days. The synthetic groundwater used by Strachan, Pederson, and Lokken (1985) contained more dissolved silica than the silicate water (Table 3 ). However, because of the higher $\mathrm{pH}$, the amount of initial dissolution was higher (compare figure 23 with Figure 24). Except for the data obtained after 180 days, the agreement between the calculated and measured release is reasonable.

\subsection{EFFECT OF GLASS COMPOSITION ON GLASS DISSOLUTION}

Once the dissolution/precipitation model was successfully applied to the actual data and agreement obtained within about $20 \%$ for most of the major 


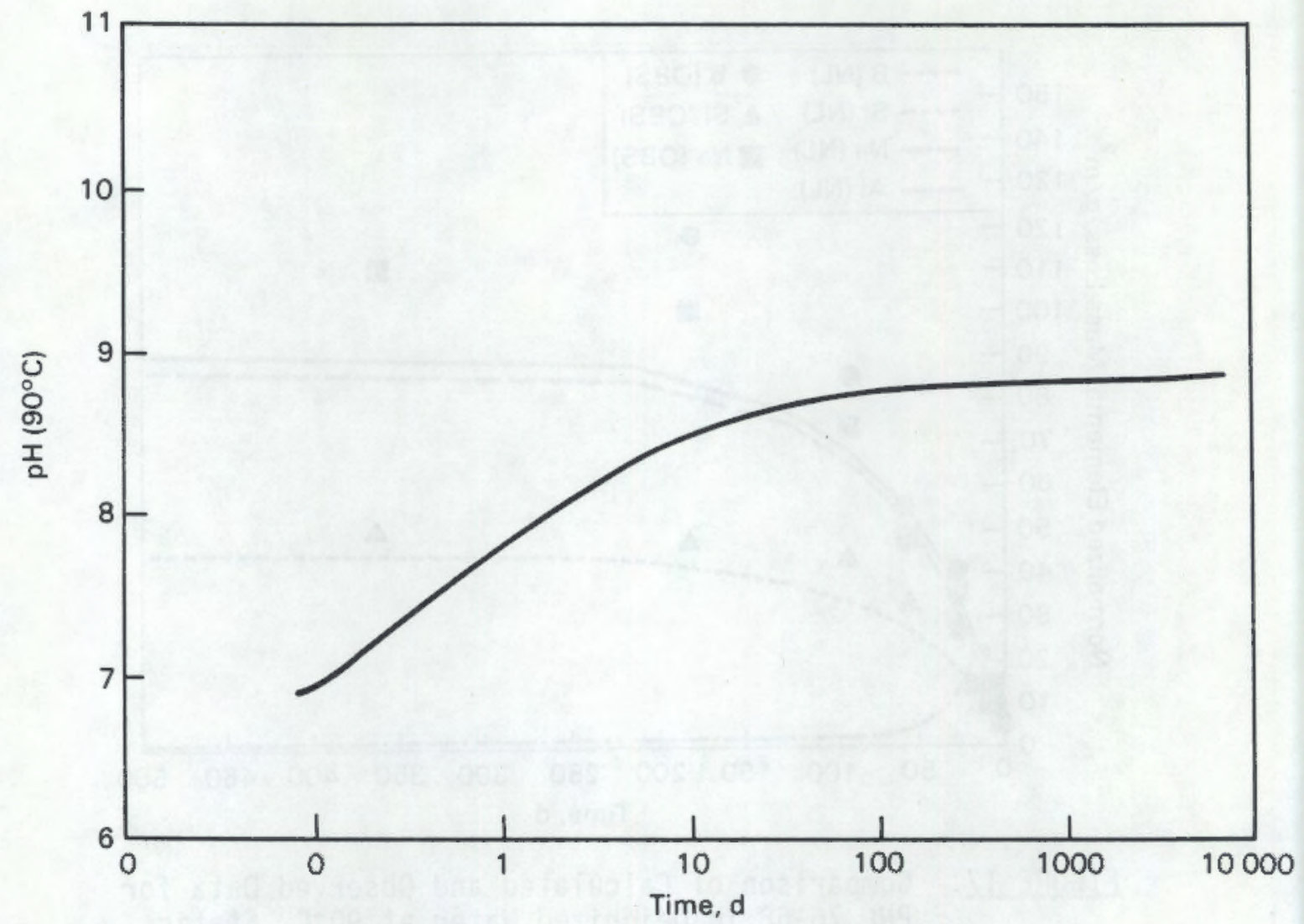

FIGURE 18. Calculated $\mathrm{pH}\left(90^{\circ} \mathrm{C}\right)$ as a Function of Time for the Djssolution of PNL 76-68 in Deionized Water; $S / V=10 \mathrm{~m}^{-1}$

components of the glass, the model could be used to expand the comparison of the three glasses discussed above to longer time periods. Specifically, the computed $B$ data for experiments at $90^{\circ} \mathrm{C}$ in deionized water from JSS-A, PNL 76-68, and SRL-131 were replotted on a plot of $\log [\mathrm{NL}(\mathrm{B})]$ versus $\log$ (time) (Figure 25) so the behavior at longer times could be shown.

Several observations can be made about the relative behavior of the three glasses evaluated. In particular, the forward dissolution rates are about equal. The results indicate that, based on the assumptions of the model, the large differences that appear at short times may nearly disappear at long times. The experience from JSS (1987) is that the final rates determined from the data appear to decrease with time or, in accelerated tests, until the detection limit is reached. For these glasses, these differences appear to disappear after about 10 years at $S / V=10 \mathrm{~m}^{-1}$. Hence, the period 


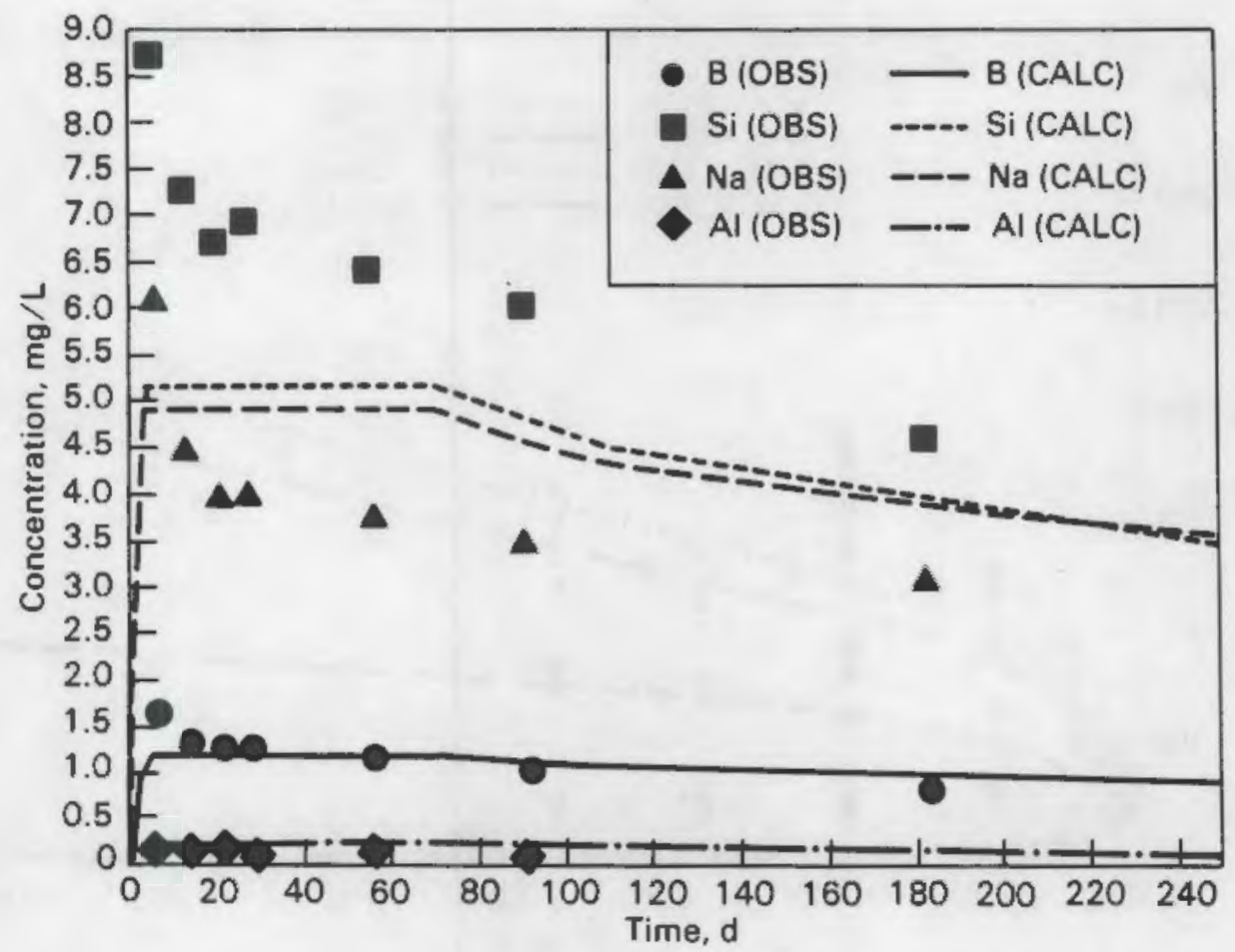

FIGURE 19. Comparison of Calculated and Observed Data for PNL 76-68 in Deionized Water at $90^{\circ} \mathrm{C}$;

Flow Rate $=1.8 \mathrm{~mL} / \mathrm{d}$

over which the major differences in the glass-to-glass behavior are expected is exactly that time period over which all glasses have been tested.

While this conclusion appears satisfactory, it should be noted that similar long-term behavior was modeled perhaps solely because the data that were modeled were essentially short term. Since most of the data available for modeling are from static leach tests at about $S / V=10 \mathrm{~m}^{-1}$ that were of 1 or at most 4 years duration, the ability of the model to predict the longterm behavior of the glasses could not be checked. To check the validity of the assumed values of the residual affinity, more work is needed at either long times or at much higher $S / V$ ratios to obtain data at high values of $(s \cdot t) / v$.

The differences that appear at short times are due to the various glass saturation concentrations (see Table 5) and the time to reach each concentration. Since the $k_{+}$values for the three glasses only span a range 


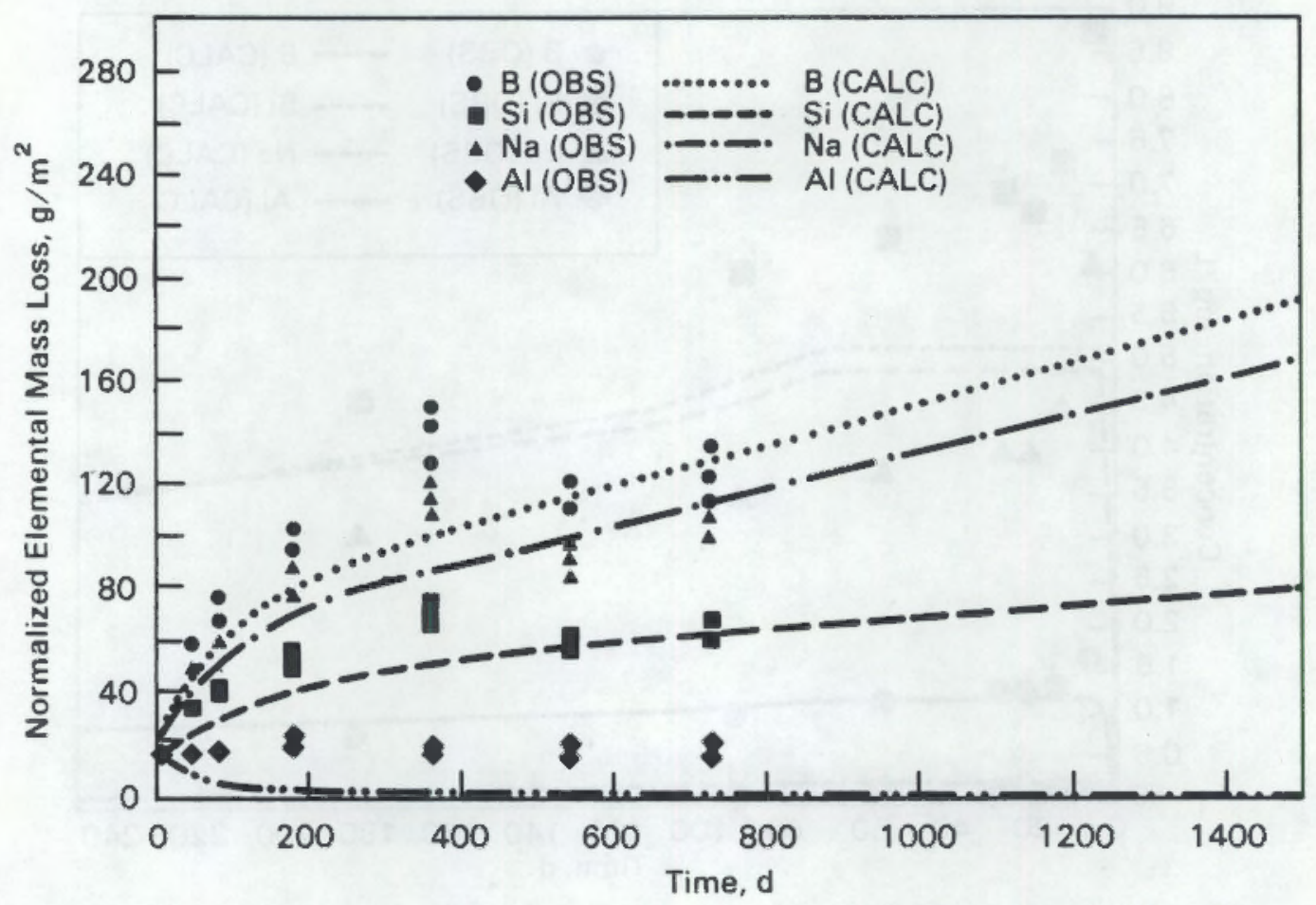

FIGURE 20. Comparison of Calculated and Observed Data for SRL-131 in Deionized Water at $90^{\circ} \mathrm{C}$, Static Conditions, and $S / V=10 \mathrm{~m}^{-1}$ (Strachan, Pederson, and Lokken 1985)

$1.4 \mathrm{~g} /\left(\mathrm{m}^{2} \cdot \mathrm{d}\right)$ to $2.3 \mathrm{~g} /\left(\mathrm{m}^{2} \cdot \mathrm{d}\right)$, the major difference between the $\mathrm{glasses}$ at short time is the saturation concentration, which, for glasses with similar values of $k_{+}$, will be reached much earlier for the glass with the lowest saturation concentration. Even though the $\log \mathrm{K}_{\text {sat }}$ is nearly the same for SRL-131 and JSS-A, saturation is reached much later for SRL-131 because SRL-131 dissolution results in a higher solution $\mathrm{PH}$ and, hence, a higher quantity of total $\mathrm{Si}$ is needed to saturate the solution.

Since the dissolved $\mathrm{H}_{4} \mathrm{SiO}_{4}$ concentration plays an important role in determining the dissolution rate of a glass at any given time, the composition of the glass has another role. As solution concentrations build, the solubilities of minerals in the data base are reached. If these phases contain sufficient silica, these phases may retard or prevent the dissolved $\mathrm{H}_{4} \mathrm{SiO}_{4}$ from reaching the saturation value for the glass. The formation of these silica-bearing phases depends on the presence of other ions, especially 


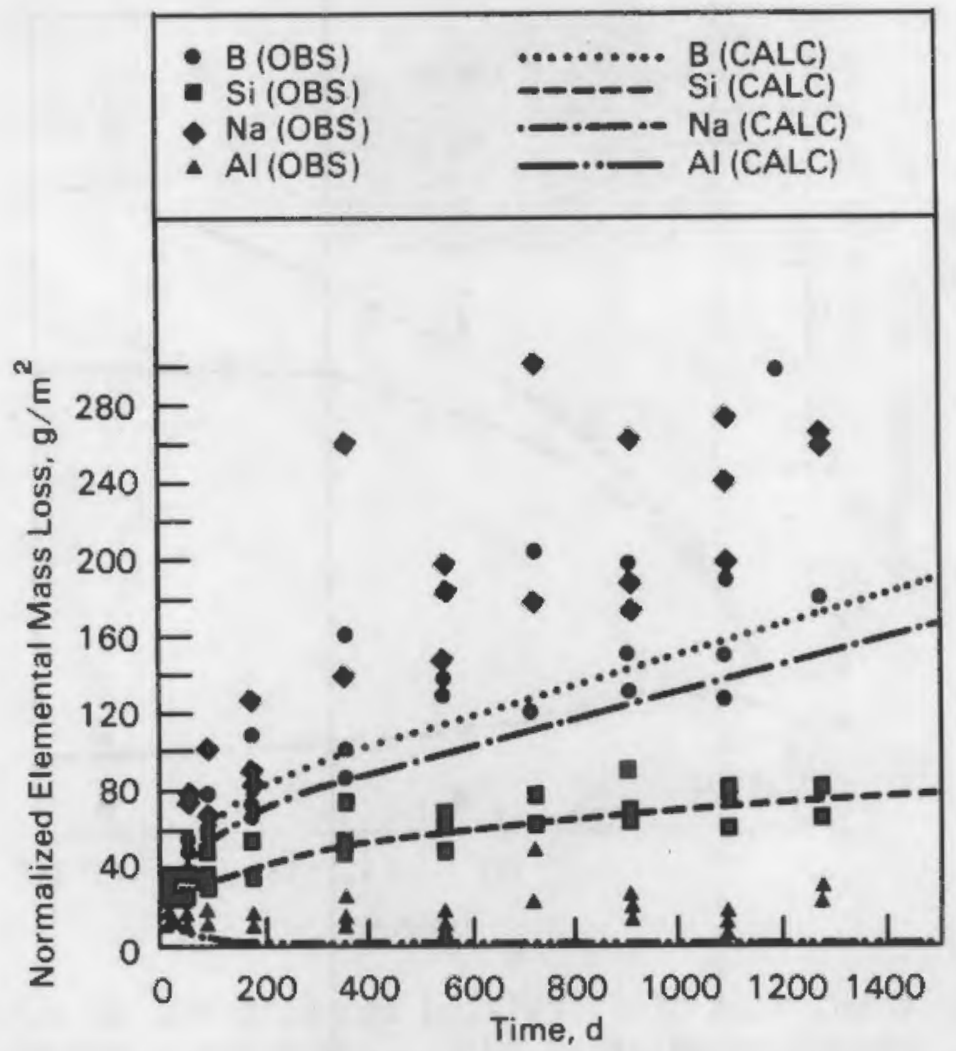

FIGURE 21. Comparison of Calculated and Observed Data for SRL-131 in Deionized Water at $90^{\circ} \mathrm{C}$, Static Conditions, and $S / N=10 \mathrm{~m}^{-1}$ (Wicks et al. 1986)

$\mathrm{Al}$ and $\mathrm{Mg}$ in the glass. However, there are indications from the literature that the effect of including $A 1$ in the glass composition has the tendency to lower the dissolution rate (e.g., Dilmore, Clark, and Hench 1979; Hench, Clark, and Yen-Bower 1979). This effect may be short term due to a decrease in the forward rate or due to the formation of a phase on the surface of the glass that limits the transport of $\mathrm{H}_{4} \mathrm{SiO}_{4}$ away from the glass. The latter appears to be the case for sepiolite, which forms when $\mathrm{Mg}$ is present in solution (Grambow and Strachan 1984) and perhaps in the glass.

The application of the glass dissolution model to various glasses under different conditions points to several critical areas in which tests are needed. In particular, static tests are needed to enhance the information on the final reaction rate. Because of the slow influx of water and the high $S / V$ ratio in a repository, the glass will dissolve at its final reaction rate 


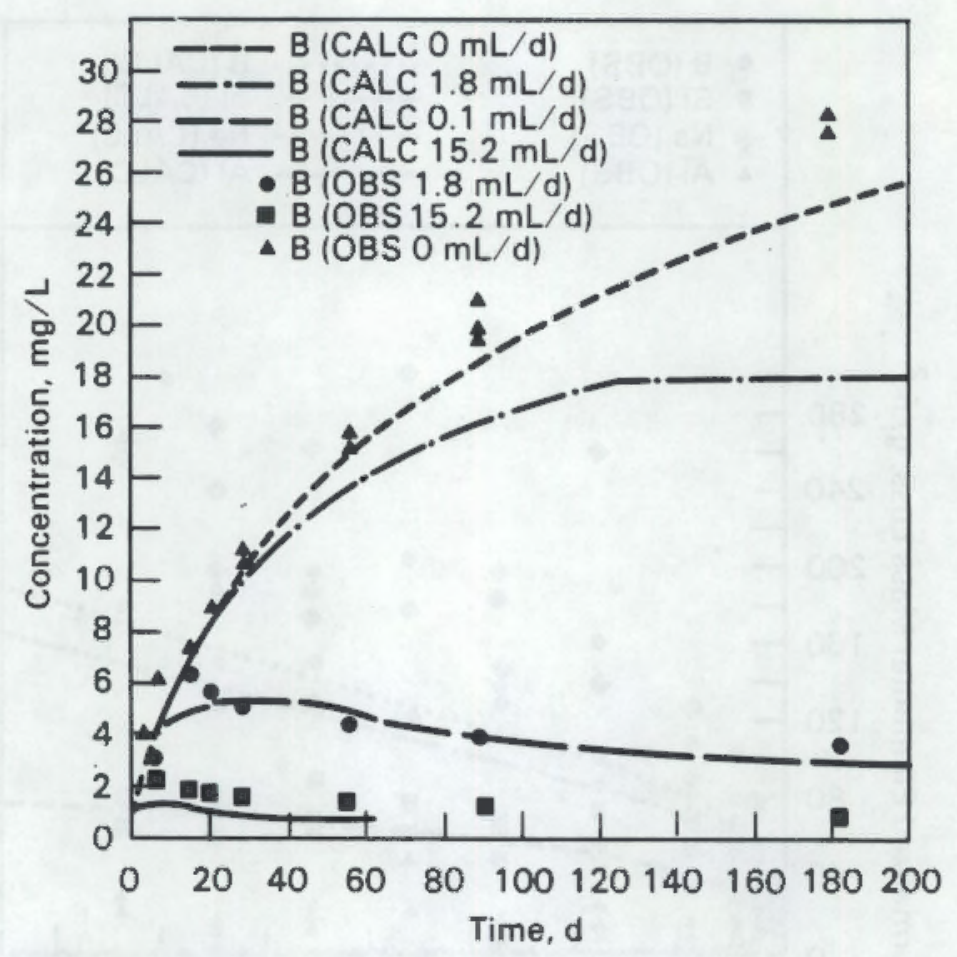

FIGURE 22. Comparison of Calculated and Observed Data for SRL-131 Deionized Water at $90^{\circ} \mathrm{C}$; Flow Rates $=0 \mathrm{~mL} / \mathrm{d}$, $1.8 \mathrm{~mL} / \mathrm{d}, 15.2 \mathrm{~mL} / \mathrm{d}$

almost upon being contacted by water. Because of the importance of the $\mathrm{H}_{4} \mathrm{SiO}_{4}$ concentration on the reaction rate, it is important that the phases that consume silica be identified. This will be more important for the longterm modeling of glass behavior than for the short-term modeling discussed in this paper. The identification of solid phases that control the solution concentrations of the other elements is also important, especially with respect to those radionuclides that could migrate to the biosphere.

\subsection{EFFECT OF SOLUTION COMPOSITION ON GLASS DISSOLUTION}

The literature contains many references that pertain to the effect of solution composition on the dissolution of nuclear waste glasses. These discussions usually center on the effect of dissolved silica on the dissolution rate (Pederson et a1. 1983; Barkatt et al. 1982; MCC 1984). In this section, this effect is discussed in terms of the modeling results. For a comparison of how a single glass behaves in different solutions (groundwaters), the 


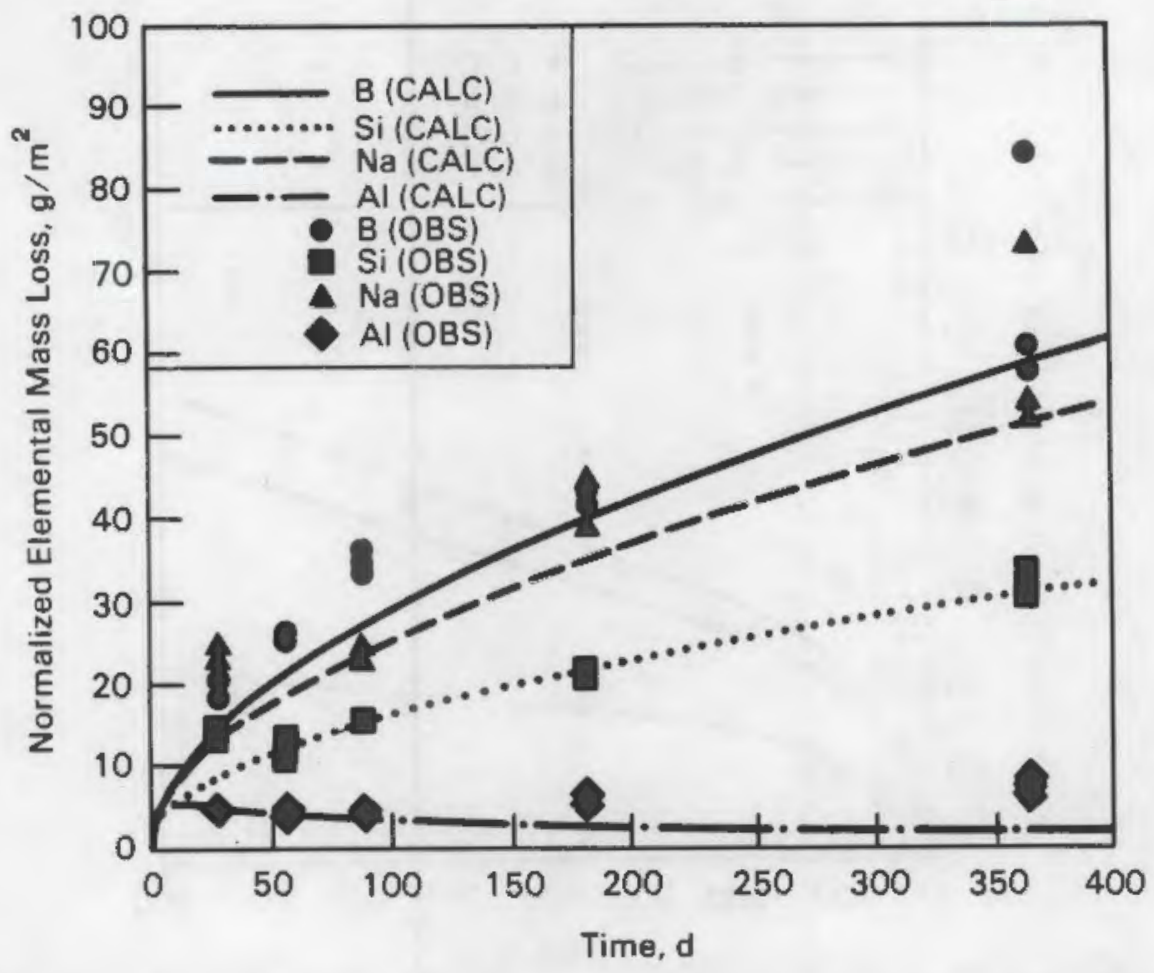

FIGURE 23. Comparison of Calculated and Observed Data for SRL'-131 in Silicate, Water at $90^{\circ} \mathrm{C}$, Static Conditions, and $S / V=10 \mathrm{~m}^{-1}$

modeled data for SRL-131 can be used. As a measure of glass dissolution, the calculated $\mathrm{pH}$ in those three solutions was plotted in Figure 26.

Figure 27 shows similar results for the $\mathrm{pH}$ at $90^{\circ} \mathrm{C}$ from the reaction of SRL-131 with the three solutions. Given sufficient time or mass of glass reacted per volume of solution, the glass will attain the same $\mathrm{pH}$ in any of the three solutions modeled.

The above calculations were made assuming certain conditions such as equilibrium with atmospheric $\mathrm{CO}_{2}(\mathrm{~g})$ and oxidizing conditions. If, as is likely to occur in a repository, some concentrations such as the dissolved carbonate are fixed by the host rock, differences in solution composition will occur among the groundwater types. Part of the reason that the three solutions yield similar $\mathrm{pH}$ values after extended reaction is the use of fixed 


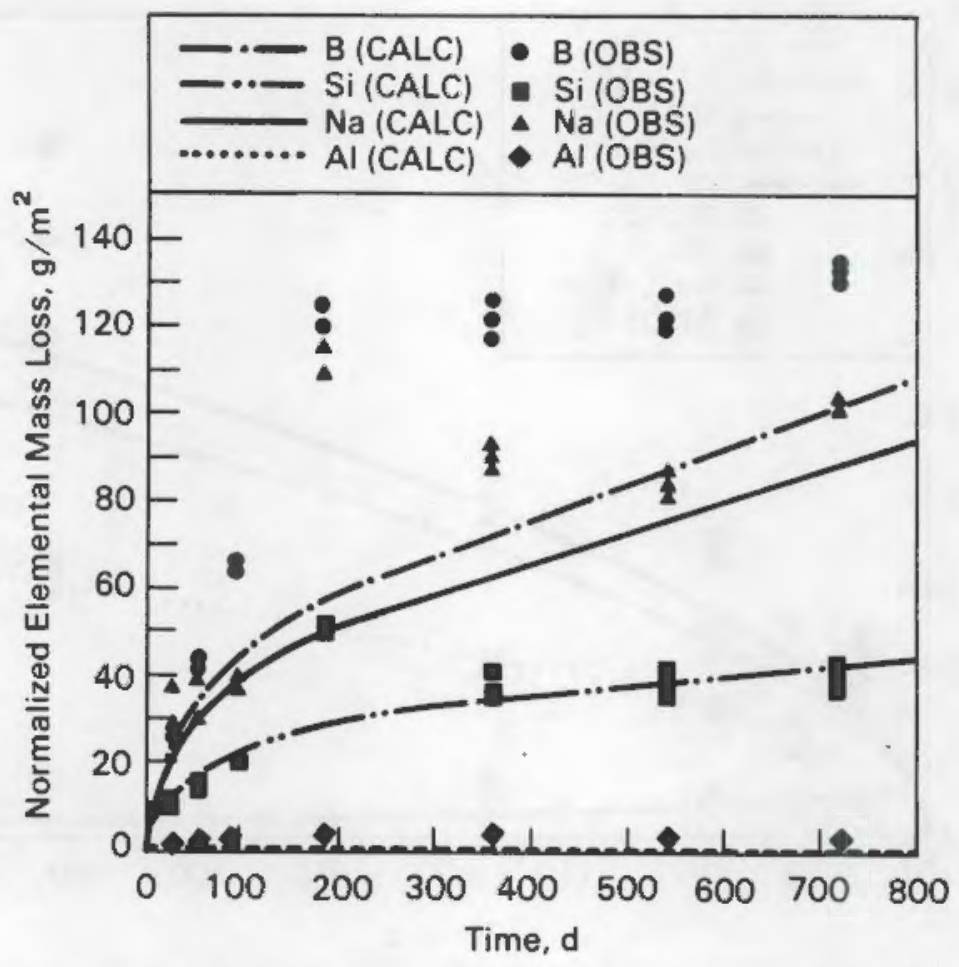

FIGURE 24. Comparison of Calculated and Observed Data for SRL-131 in Synthetic Groundwater at $90^{\circ} \mathrm{C}$, Static Conditions, and $S / V=10 \mathrm{~m}^{-1}$

atmospheric $\mathrm{CO}_{2}(\mathrm{~g})$. However, at very long reaction times and slow flow rates, the chemistry of the solution is dominated by the dissolved glass, and $\mathrm{CO}_{2}(\mathrm{~g})$ plays only a minor role.

The results of modeling the $B$ release of SRL-131 into the three solutions supports the arguments made using the calculated $\mathrm{pH}$ (Figure 26). However, the solubility of the various components of the glass may differ dramatically from one solution to the next. The final dissolution rate of the glass matrix is not expected to be a sensitive function of the solution composition within the frame of naturally occurring groundwaters. 


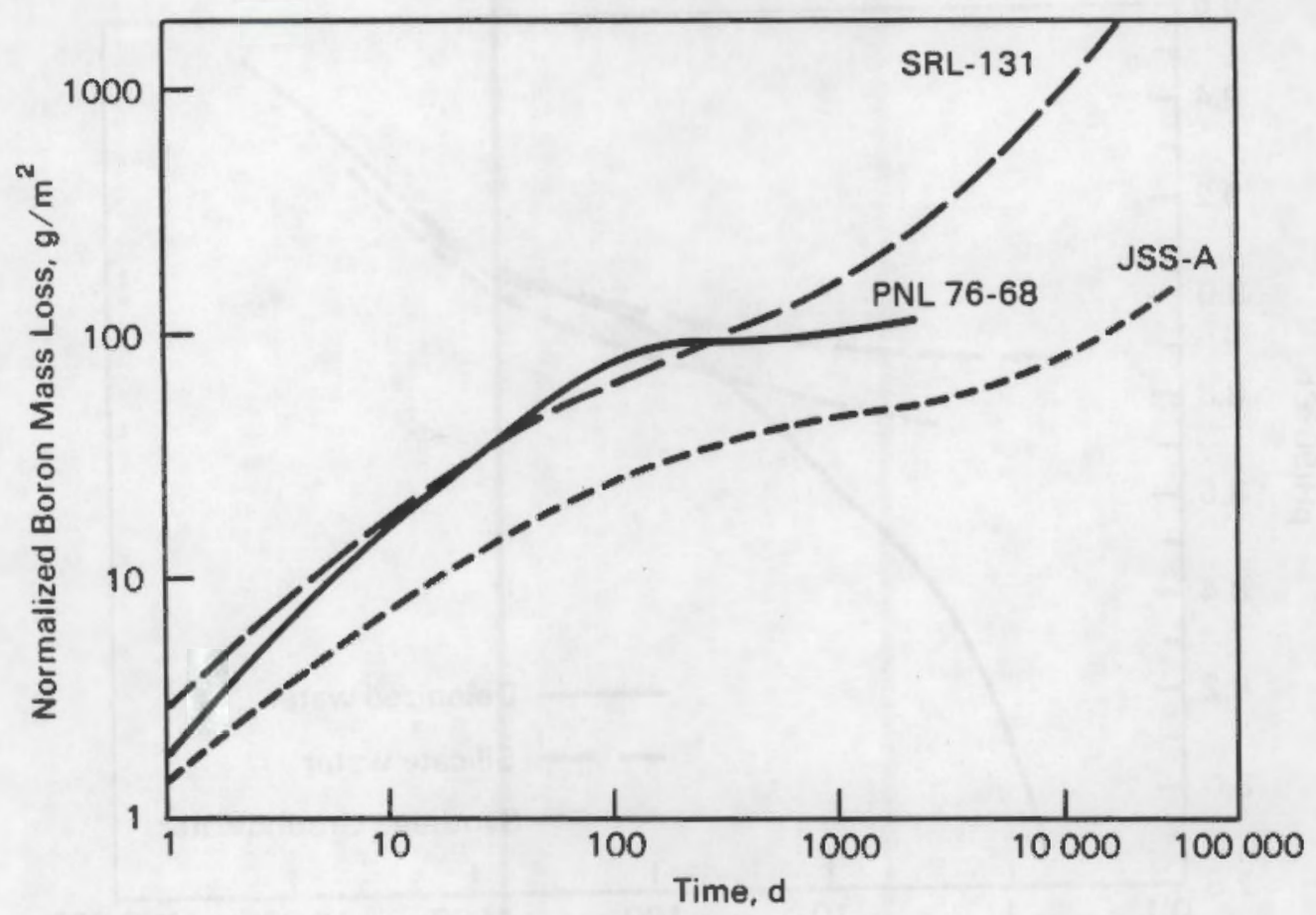

FIGURE 25. Calculated Normalized Boron Mass Loss for JSS-A, PNL 76-68, and SRL-131 


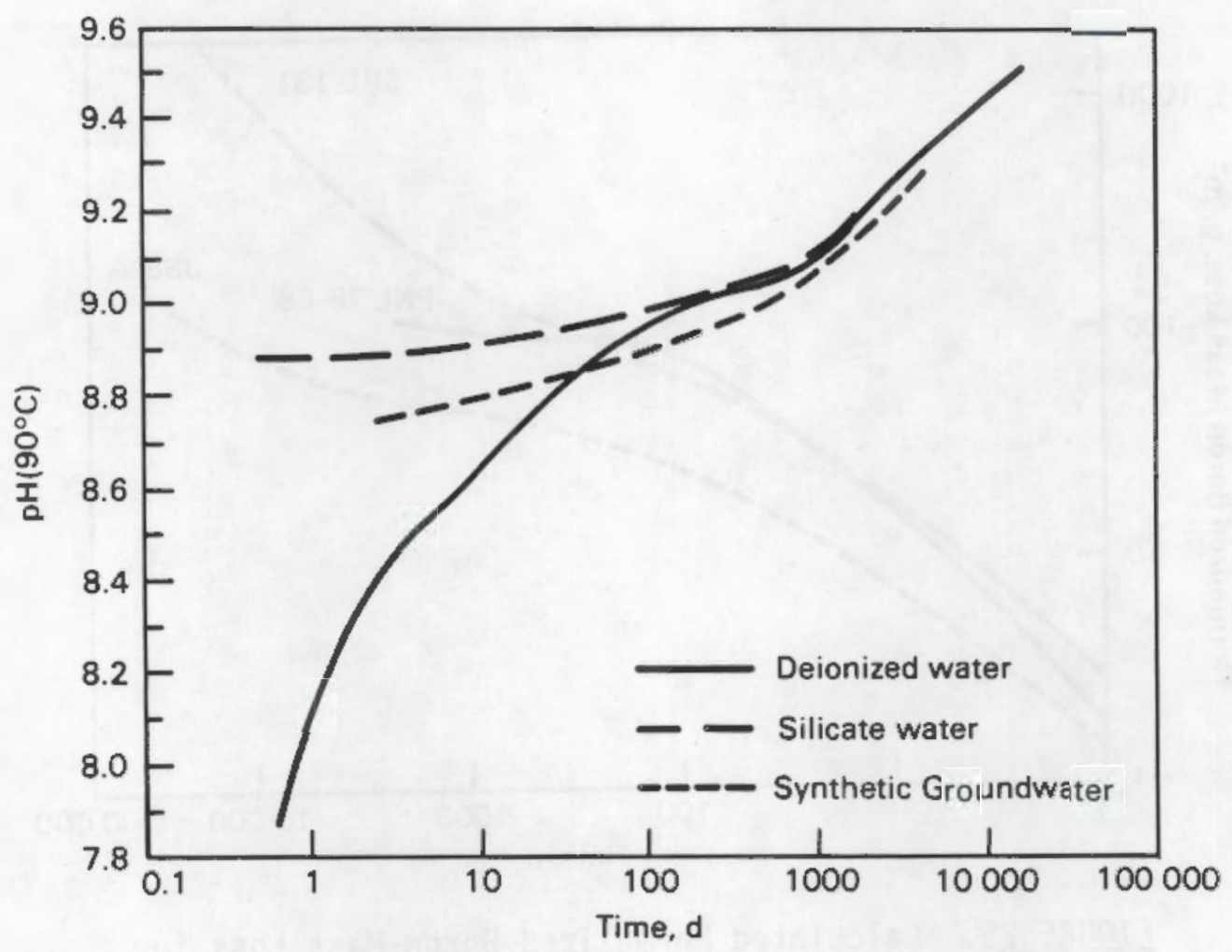

FIGURE 26. Calculated $\mathrm{pH}\left(90^{\circ} \mathrm{C}\right)$ for SRL-131 in Deionized Water, Silicate Water, and Synthetic Groundwater, as a Function of Time 


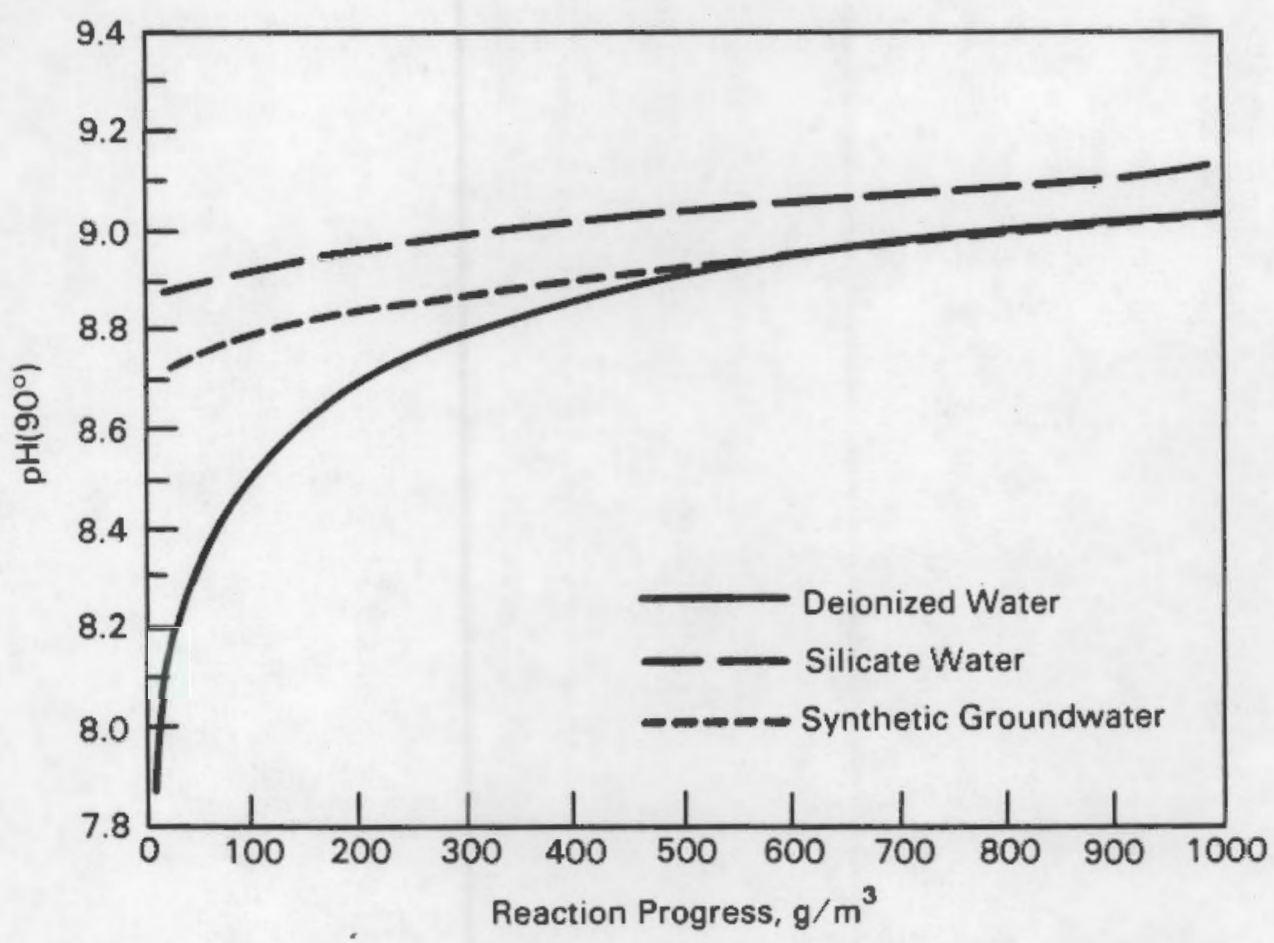

FIGURE 27. Calculated $\mathrm{pH}\left(90^{\circ} \mathrm{C}\right)$ for SRL-131 in Deionized Water, Silicate Water, and Synthetic Groundwater, as a Function of Reaction Progress 


\subsection{FUTURE WORK}

The model presented in this document depends on four constants to define the dissolution of glass in aqueous solutions. Of these constants, three can be measured using wel1-controlled laboratory experiments. Oniy the diffusion of silicic acid in the gel layer appears to be determined by inference; that is, the mechanism by which silicic acid is transported through or retarded by the gel layer constituents is not known. However, carefully controlled experiments conducted separately from glass dissolution experiments may be defined to elucidate this mechanism. These controlled experiments must be identified and performed to verify the model or to refine it.

The effect of redox potential on glass dissolution also needs to be understood in the same manner that the effects of bentonite and/or corrosion products are currently understood (JSS 1987). This information is needed for predicting glass performance under various geologic conditions.

While the choice of minerals for input to the model appears satisfactory for the agreement between calculated and available data, the mineral phases have only been inferred from solution analyses. For the most part, these phases still are not known, or efforts have not been made to identify the phases that control solution concentrations. Work toward identifying these phases would lead to more complicated questions related to kinetics and thermodynamics; however, without this information, it may not be possible to address the more specific regulatory concern of the long-term performance of glass in geologic storage.

Finally, it seems prudent to validate the model using natural analogues, in particular, the history of the storage environment. Whether or not natural analogues are considered, the model is a very valuable tool for understanding how manmade glasses will interact with the environment in which they are stored. After all, the future of manmade glasses in manmade repositories is subject to nearly the same uncertainties as the evolution of natural analogues and the natural repositories. By regulation, science has 
been mandated to predict the future almost with more certainty than it is a) Towed to understand and use geologic evolution. 


\subsection{REFERENCES}

Barkatt, Aa., P. B. Macedo, B. C. Gibson, and C. J. Montrose. 1985.

"Modelling of Waste Form Performance and System Release." In Scientific

Basis for Nuclear Waste Management VIII, eds. C. M. Jantzen, J. A. Stone, and R. C. Ewing. Materials Research Society, Pittsburgh, Pennsylvania.

Buckwalter, C. Q., and L. R. Pederson. 1982, "Inhibition of Nuclear Waste Glass Leaching by Chemisorption." J. American Ceramic Society 65(9):431-436.

Bunker, B. C., G. W. Arno]d, E. W. Beauchamp, and D. E. Day. 1983. "Mechanisms for Alkali Leaching in Mixed Na-K-Silicate Glasses."

Non-Crystall ine Solids 58:295-322.

Chick, L. A., A. M. Bowen, R. 0. Lokken, J. W. Wald, L. R. Bunne11, and D. M. Strachan. 1984. West Valley High-Level Nuclear Waste Glass Development: A Statistically Designed Mixture Study. PNL-4992, Pacific Northwest Laboratory, Richland, Washington.

Chick, L. A., and L. R. Pederson. 1984. "The Relationship Between Reaction Layer Thickness and Leach Rate for Nuclear Waste Glasses." In Scientific Basis for Nuclear Waste Management VII, ed. G. L. McVay. Elsevier Publishing Co., New York.

Chick, L. A., and R. P. Turcotte. 1983. Glass Leaching Performance.

PNL-4576, Pacific Northwest Laboratory, Richland, Washington.

Clark, D. E., C. A. Maver, A. R. Jurgensen, and L. Urwongse. 1982. "The Effects of Waste Composition and Loading on the Chemical Durability of a Borosilicate GTass." In Scientific Bas is for Nuclear Waste Management $V$, ed. W. Lutze. North-Holland, New York.

Conradt, R., H. Roggendorf, and H. Scholze. 1986. "Investigations on the Role of Surface Layers in HLW Glass Leaching." In Scientific Basis for Nuclear Waste Management IX, ed. L. 0. Werme. Materials Research Society, Pittsburgh, Pennsylvania.

Dilmore, M. F., D. E. Clark, and L. L. Hench. 1979. "Corrosion Behavior of Lithia Disilicate Glass in Aqueous Solutions of Aluminum Compounds." American Ceramic Society Bulletin 58:1111-1114, 1117, 1124.

Freude, E., B. Grambow, W. Lutze, H. Rabe, and R. C. Ewing. 1985. "LongTerm Release From High Level Waste Glass - Part IV: The Effect of Leaching Mechanism." In Scientific Basis for Nuclear Waste Management VIII, eds. C. M. Jantzen, J. A. Stone, and R. C. Ewing. Materials Research Society, Pittsburgh, Pennsylvania.

Fullam, H. T. 1982. "Solubility Effects in Waste Glass/Demineralized Water Systems." In Scientific Basis for Nuclear Waste Management, ed. S. V. Topp. North-Holl and, New York. 
Grambow, B. 1982. "The Role of Metal Ion Solubility in Leaching of Nuclear Waste Glasses." In Scientific Basis for Nuclear Waste Management $V$, ed. W. Lutze. North-Holland, New York.

Grambow, B. 1983a. "Geochemical Modeling of the Reaction Between Glass and Aqueous Solution." In Advances in Ceramics - Nuclear Waste Management, eds, G. G. Wicks and W. A. Ross, Vol. 8. American Ceramic Society, Columbus, Ohio.

Grambow, B. 1983b. "Influence of Saturation on the Leaching of Borosilicate Nuclear Waste Glasses." Glastechnische Berichte XIII. Internationaler Glaskongress $56: 566-571$.

Grambow, B. 1984. Ein Physikalisch-Chemisches Modell fuer den Mechanismus der Glaskorrosion unter besonderer Beruecksichtigung Simulierter Radioaktiver Abfallglaeser. Doctoral thesis from the Freien Universitaet Berlin, Berlin, Federal Repubi ic of Germany.

Grambow, B. 1985. "A Genera] Rate Equation for Nuclear Waste Glass Corrosion." In Scientific Basis for Nuclear Waste Management VIII, eds. C. M. Jantzen, J. A. Stone, and R. C. Ewing. Materials Research Society, Pittsburgh, Pennsylvania.

Grambow, B. 1987. JSS-A Glass Dissolution: Mechanism, Model and Experiment. SKB Technical Report 87-02, Swedish Nuclear Fuel and Waste Management Co., Stockholm, Sweden.

Grambow, B., and D. M. Strachan. 1984. "Leaching of Nuclear Waste Glasses Under Near-Saturation Conditions." In Scientific Basis for Nuclear Waste Management VII, ed. G. L. McVay, North-Holland, New York.

Grambow, B., H-P. Hermansson, I-K. Bjoerner, and L. 0. Werme. 1986a. "Glass/Water Reaction in Presence of Granite and Bentonite - Experiment and Mode1." In Scientific Basis for Nuclear Waste Management IX, eds. L. 0. Werme. Materials Research Society, Pittsburgh, Pennsylvania.

Grambow, B., M. J. Jercinovich, R. C. Ewing, and C. D. Byers, 1986b. "Weathered Basalt Glass: A Natural Analogue for the Effects of Reaction Progress on Nuclear Waste Glass Alteration." In Scientific Bas is for Nuclear Waste Management IX, ed. L. 0. Werme. Materials Research Society, Pittsburgh, Pennsylvania.

Harvey, K. B., C. D. Litke, and C. A. Boase. 1984. "Diffusion-Based Leaching Models for Waste Forms." In Advances in Ceramics. Nuclear Waste Management Vol. 8, eds. G. G. Wicks and W. A. Ross. American Ceramic Society, Columbus, Ohio. 
Hench, L. L., D. E. Clark, and E. L. Yen-Bower. 1979. "Surface Leaching of Glasses and Glass-Ceramics." In Proceedings of the Conference on High-Level Radioactive Solid Waste Forms, ed. L. A. Casey. NUREG/CP-0005, U.S. Nuclear Regulatory Agency, Washington, DC.

Japanese, Swedish, and Swiss (JSS) Project. 1984. JSS Project Phase I, A Summary of Work Performed at Studevik Energitcknik $A B$ and at the Swiss Federal Institute for Reactor Research (EIR). SKB Technical Report 84-03, Swedish Nuclear Fuel and Waste Management Co., Stockholm, Sweden.

Japanese, Swedish, and Swiss (JSS) Project. 1986. Final Report USS Project Phase III: Static Corrosion of Radioactive Glass at $40^{\circ} \mathrm{C}$ and Corrosion of Radioactive Glass under Dynamic Conditions. SKB Technica1 Report 86-01, Swedish Nuclear Fuel and Waste Management Co., Stockholm, Sweden.

Japanese, Swedish, and Swiss (JSS) Project. 1987. JSS-Project Phase IV Final Report. Experimental and Modelling Studies of HLW Glass Dissolution in Repository Environments. SKB Technical Report 87-01, Swedish Nuciear Fuel and Waste Management $\mathrm{C}_{0}$. , Stockholm, Sweden.

Johnston, J. W., and J. L. Danie1. 1982. Summary Report for the Interlaboratory Round Robin of the MCC-1 Static Leach Test Method. PNL-4249, Pacific Northwest Laboratory, Richland, Washington.

Kuhn, W. L., and R. D. Peters. 1983. "Leach Models for a Commercial Nuclear Waste Glass." In Scientific Basis for Nuclear Waste Management VI, ed. D. G. Brookins. North-Holland, New York.

Lutze, W., G. Malow, and H. Rabe. 1983. "Surface Layer Formation on a Nuclear Waste Glass." In Scientific Basis for Nuclear Waste Management VI, ed. D. G. Brookins. North-Holl and, New York.

Machiels, A. J., and C. Pescatore. 1982. Modeling of Waste Form Leaching. Part II: Mechanistic Modeling of Nuclear Waste Form Leaching by Aqueous Solutions. UILU-ENG-82-5360 (REV.7/83), University of I1linois, Urbana, Illinois.

Malow, G. 1982. "The Mechanisms for Hydrothermal Leaching of Nuclear Waste Glasses: Properties and Evaluation of Surface Layers." In Scientific Basis for Nuclear Waste Management $v$, ed. W. Lutze. North-Holland, New York.

Materials Characterization Center (MCC). 1981. Nuclear Waste Materials Handbook. DOE/TIC-11400, Prepared for the U.S. Department of Energy by Pacific Northwest Laboratory, Richland, Washington.

Materials Characterization Center (MCC). 1984. Final Report of the Defense High-Level Waste Leaching Mechanisms Program. PNL-5157, Pacific Northwest Laboratory, Richland, Washington. 
McGrail, B. P., L. R. Pederson, D. M. Strachan, R. C. Ewing, and L. S. Corde11. 1988. "Obsidian Hydration Dating - Field, Laboratory, and Modeling Results." Materials Issues in Art and Archaeology. Materials Research Society, Pittsburgh, Pennsylvania.

Parkhurst, D. L., D. C. Thorstenson, and L. N. Plummer. 1980. PHREE0E - A Computer Program for Geochemical Calculations. USGS/WRI-80-96, U.S. GeoTogical Survey, Reston, Virginia. [This code has been modified for the following: 1) Automatic reaction progress calculations by $\mathrm{Dr}$. Peter offerman, Hahn-Meitner Institute, Berlin, FRG, and 2) Replacement of the thermodynamic data base with the data base from MINTEQ by K. M. Krupka and W. M. Howden, Pacific Northwest Laboratory.]

Pederson, L. R., C. Q. Buckwalter, G. L. McVay, and B. L. Riddle. 1983. "Glass Surface Area to Solution Volume Ratio and Its Implications to Accelerated Leach Testing." In Scientific Basis for Nuclear Waste Management VI, ed. D. G. Brookins. North-Holland, New York.

Plodinec, M. J., C. M. Jantzen, and G. G. Wicks. 1984. "Thermodynamic Approach to Prediction of the Stability of Proposed Radwaste Glasses." In Advances in Ceramics - Nuclear Waste Management, eds. G. G. Wicks and W. A. Ross, Vol. 8. The American Ceramic Society, Columbus, Ohio.

Plodinec, M. J. 1980. "Improved Glass Compositions for Immobilization of SRP Waste." In Scjentific Basis for Nuclear Waste Management II, ed. C.J.M. Northrup. Plenum, New York.

Pritchard, R. G., J. R. Cann, and D. A. Wood. 1978. Initial Reports of the Deep Sea Drilling. Project 49:709.

Ross, H. A., D. J. Bradley, L. R. Bunne11, W. J. Gray, Y. B. Katayama, G. B. Mellinger, J. E. Mende1, F. P. Roberts, R. P. Turcotte, J. W. Wald, W. E. Weber, and J. H. Westsik, Jr. 1978. Annual Report on the Characteristics of High-Level Waste Glasses. PNL-2625, Pacific Northwest Laboratory, Richland, Washington.

Shade, J. W., and D. M. Strachan. 1986. "Effect of High Surface Area to Solution Volume Ratios in Waste Glass Leaching." Bullet in of the American Ceramic Society 65(12):1568-1573.

Soper, P. D., D. D. Walker, J. M. Plodinec, G. J. Roberts, and L. F.Lightner. 1983. "Optimization of Glass Composition for the Vitrification of Nuclear Waste at the Savannah River Plant." Bulletin of the American Ceramic Society 62:1013-1018.

Strachan, D. M. 1983. "Resu1ts from Long-Term Use of the MCC-1 Static Leach Test Method." Nuclear and Chemical Waste Management 4:177-188.

Strachan, D. M. 1984. "The Effect of Flow Rate on the Leaching of Nuclear Waste Glass." In Advances in Ceramics - Nuclear Waste Management Vol. 8, eds. G. G. Wicks and W. A. Ross. The American Ceramic Society, Columbus, Ohio. 
Strachan, D. M., and G. J. Exarhos. 1981. "Standard Tests for Nuclear Waste Materials II:. MCC-4 Low Flow Leach Test." PNL-SA-9487, Pacific Northwest Laboratory, Richland, Washington.

Strachan, D. M., K. M. Krupka, and B. Grambow. 1984. "Solubility Interpretations of Leach Tests on Nuclear Waste Glass." Nuclear and Chemical Waste Management 5:87-99.

Strachan, D. M., L. R. Pederson, and R. 0. Lokken. 1985. Results from the Long-Term Interactions and Modeling of SRL-131 Glass with Aqueous Solutions. PNL-5654, Pacific Northwest Laboratory, Richland, Washington.

Van Iseghem, P., and B. Grambow. 1988. "The Long-Term Corrosion and Modelling of Two Simulated Belgian Reference High-Level Waste Glasses." In Scientific Basis for Nuclear Waste Management XI, eds. M. J. Apted and R. E. Westerman. Materials Research Society, Pittsburgh, Pennsylvania.

Wallace, R. M., and G. G. Wicks. 1983. "Leaching Chemistry of Defense Borosilicate Glass." In Scientific Basis for Nuclear Waste Management VI, ed. D. G. Brookins. North-Holland, New York.

Wicks, G. G., J. A. Stone, G. T. Chandler, and S. Williams. 1986. Long-Term Leaching Behavior of Simulated Savannah River Plant GIass. Part I: MCC-1 Leachability Results, Four-Year Leaching Data. E. I. duPont de Nemours and Co., Savannah River Laboratory, Aiken, South Carolina. 


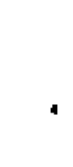




\section{DISTRIBUTION}

No. of

Copies

\section{QFFSITE}

D. H. Alexander

U.S. Department of Energy

\section{RW-24}

Washington, DC 20545

C. Cooley

U.S. Department of Energy $\mathrm{RW}-43$

Washington, DC 20545

M. W. Frei

Office of Civilian Radioactive Waste Management RW-23

U.S. Department of Energy

Washington, DC 20545

H. Jaffee

International Research and Development Policy

Office of Assistant Secretary for International Affairs IE-12

U.S. Department of Energy

Washington, DC 20545

S. Russo, Director

Office of Civilian Radioactive Waste Management RW-1

U.S. Department of Energy

Washington, DC 20545

10 DOE Office of Scientific and Technical Information

H. Barnes

Pennsylvania State University University Park, PA 16802

\section{A. Barkatt}

Vitreous State Laboratory

Keane Hall

Catholic University of America

Washington, DC 20064
No, of

Copies

J. K. Bates

Argonne National Laboratory

9700 South Cass Avenue

Argonne, IL 60439

M. J. Bell

U.S. Nuclear Regulatory Cominission Washington, DC 20555

N. E. Bibler

E. I. duPont de Nemours and $\mathrm{Co}$. , Inc.

Savannah River Laboratory

Aiken, SC 29808-0001

L. Brush

Sandia National Laboratory

P.0. Box 5800

Albuquerque, NM 87107

W. E. Coons

IT Corporation

2340 Alamo SE

Albuquerque, NM 87106

G. A. Dinwiddie

U.S. Geological Survey

U.S. Department of the Interior

National Center, MS-410

12202 Sunrise Valley Drive

Reston, VA 22092

R. C. Ewing

Department of Geology

University of New Mexico

Albuquerque, NM 87131

D. E. Grandstaff

Department of Geology

Temple University

Philadelphia, PA 19122 
No. of

Copies

J. C. Haugen

U.S. Department of Energy

Chicago Operations Office

9800 South Cass Avenue

Argonne, IL 60439

G. Jacobs

Oak Ridge National Laboratory

P.0. Box $X$

Bethel Valley Road

MS 038, BTdg. 1505

Oak Ridge, TN 37831

K. J. Jackson

Lawrence Livermore National Laboratory

University of California

P.0. Box 808

Livermore, CA 94550

C. M. Jantzen

E. I. duPont de Nemours and Co., Inc.

Savannah River Laboratory

Aiken, SC 29808-0001

K. S. Kim

U.S. Nuclear Regulatory Commission

Washington, DC 20555

J. L. Knabenschuh

West Valley Nuclear Services

Co., Inc.

P.0. Box 191

West Valley, NY 14171-0191

P. B. Macedo

Vitreous State Laboratory

Keane Hall

Catholic University of America

P.0. Box 1663

Washington, DC 20064

A. J. Machiels

Electric Power Research Institute

P.0. Box 10412

Palo Alto, CA 94303
No. of

Copies

M. A. Molecke

Sandia National Laboratory

P.0. Box 5800

Albuquerque, NM 87107

H. E. Nuttall

Nuttall and Associates, Inc.

1445 Honeysuck le Drive, NE

A1buquerque, NM 87122

N. Patera

U.S. Department of Energy

Chicago Operations office

6800 South Cass Avenue

Argonne, IL 60439

C. Pescatore

Brookhaven National Laboratory

Upton, NY 11973

T. H. Pigford

Department of Nuclear

Engineering

University of California

Berkeley, CA 94720

M. J. Plodinec

E. I. duPont de Nemours and $\mathrm{Co}$, , Inc.

Savannah River Laboratory

Aiken, SC 29808-0001

J. M. Pope

West Valley Nuclear Services

Co., Inc.

P.0. Box 191

West Valley, NY 14171-0191

J. Rotert

U.S. Department of Energy

Nevada Operations Office

P.0. Box 14100

Las Vegas, NV 89114-4100

W. B. Seefeldt

Argonne National Laboratory 9700 South Cass Avenue

Argonne, IL 60439 
No. of

Copies

H. Shaw

Lawrence Livermore National Laboratory

University of California

P.0. Box 808

Livermore, CA 94550

M. J. Steindler

Argonne Nationa] Laboratory

9700 South Cass Avenue

Argonne, IL 60439

J. A. Stone

E. I. duPont de Nemours and Co., Inc.

Savannah River Laboratory

Aiken, SC 29808-0001

G. G. Wicks

E. I. duPont de Nemours and Co., Inc.

Savannah River Laboratory

Aiken, SC 29808-0001

W. B. White

Pennsylvania State University University Park, PA 16802

T. J. Wolery

Lawrence Livermore National Laboratory

University of California

P.0. $80 \times 80 B$

Livermore, CA 94550

\section{FORE IGN}

Jordi Bruno

Department of Inorganic Chemistry

Royal Institute of Technology

S-100 44

Stockholm, Sweden

Gerhard Bart

Swiss Federal Institute for Reactor Research

$\mathrm{CH}-5303$ Würenlingen

Switzerland
No. of

Copies

Inga-Kari Bjorner

Studsvik Energitseknik $A B$

S-611 82 Nyköping

Sweden

Hubert Christenson

Studsvik Energitseknik $A B$

S-611 82 Nyköping

Sweden

Roy Forsyth

Studsvik Energitseknik $A B$

S-611 82 Nyköping

Sweden

Noel Jacquet-Francillon

Centre D'Études Nucléaires de la Vallée du Rhone

BP 171-30205

Bagnols-sur-Céze

Cédex, France

N. C. Garisto

AECL - Whiteshell Nuclear Research Establishment

Pinawa, Manitoba, ROE ILO

Canada

10 Bernd Grambow

Hahn-Meitner Institut fur Kernforschung

Glienicker Strasse 100

D1000 Berlin 39

Federal Republic of Germany

K. Harvey

Atomic Energy of Canada

Pinawa, Manitoba, ROE ILO

Canada

P. J. Hayward

Atomic Energy of Canada

Pinawa, Manitoba, RDE 1Lo

Canada 
No. of

Copies

L. Johnson

Atomic Energy of Canada

Pinawa, Manitoba, ROE 1 LO

Canada

Lothar Kahl

KFK

Postfach 3640

D-7500 Karlsruhe 1

Federal Republic of Germany

S. J. Liu

Radjoactive Waste Management Division

Institute of Nuclear Energy Research

P.0. Box 3-27

Lung Tan, Taiwan 325

Werner Lutze

Hahn-Mejtner Institut fur Kernforschung

Glienicker Strasse 100

Dl000 Berlin 39

Federal Republic of Germany

C. McCombie

NAGRA

Parkstrasse 23

$\mathrm{CH}-5401$ Baden

Switzertand

I. McKinley

NAGRA

Parkstrasse 23

CH-5401 Baden

Switzerland

T. Mishima

Deputy General Manager

Waste I solation Office

Waste Management and Row

Materials Division

Power Reactor and Nuclear Fuel

Development Corporation

1-9-13 Akasaka, Minato-ku

Tokyo 107

Japan
No. of

Copies

Junichi Nunomura

Mitsubishi Corporation

6-3, Marunouchi 2-chome

Chiyoda-ku, Tokyo

Japan

Tadashi Nagakura

Central Research Institute of Electric Power Industry

1-6-1 0htemach $i$

Chiyoda-ku, Tokyo 100

Japan

J. - C. Petit

CEN Fontenany

BP 692265 Fontenay-aux-Roses

Cédex, France

Horst Pentinghaus

KFK

Postfach 3640

D-7500 Karlsruhe 1

Federal Republic of Germany

Edwin Schiewer

Hahn-Meitner Institut fur Kernforschung

Glienicker Strasse 100

Dl000 Berlin 39

Federal Republic of Germany

Seichi Sato

Kyushu University

Department of Nuclear Engineering

Fukuoka, Japan

Masaki Tsukamoto

Central Research Institute of Electric Power Industry

2-11-I IWAT0 Kita

Komae-Shi

Tokyo 201

Japan 
No. of

Copies

H. Wanner

Nuclear Energy Agency

Data Bank

Batiment 445

91191 Gif-sur-Yvette

Cédex, France

L. 0 . Werme

SKB

Box 5864

S-102 48 Stockho7m

Sweden

\section{ONSITE}

5 DOE Richland Operations office

E. A. Bracken

R. W. Brown

D. C. Langstaff

D. M. Smith

J. D. White

2 Westinghouse Hanford $\mathrm{CO}_{2}$

M. J. Kupfer

W. W. Schultz

45 Pacific Northwest Laboratory

M. K. Altenhofen

M. J. Apted
No. of

Copies

S. 0. Bates

D. J. Bradley

P. G. Doctor

D. W. Enge]

R. L. Erikson

T. E. Gates

J. H. Jarrett

M. R. Kreiter

K. M. Krupka

W. L. Kuhn

A. M. Liebetrau

J. L. McElroy

P. B. McGrail

G. L. McVay

G. B. Mellinger

J. E. Mendel

L. R. Pederson

R. D. Peters

D. Rai

M. A. Reimus

P. W. Reimus

R. J. Serne

J. W. Shade

S. C. Slate

J. L. Straalsund

D. M. Strachan (10)

C. K. Thornhill

A. E. Van Luik Publishing Coordination Technical Report Files (5) 
